\title{
La participación como derecho en la preservación del patrimonio cultural de Santa Cruz desde una doble perspectiva: la legal y la de los actores involucrados en Puerto Deseado y Río Gallegos (2010-2018)
}

\author{
Participation as a right in the preservation of Santa Cruz's cultural heritage from a \\ double pespective: the legal one and that of the actors involved in Puerto Deseado and \\ Río Gallegos (2010-2018) \\ Graciela Ciselli, Antonella Duplatt, Marcelo Hernández \\ graciselli@hotmail.com,antoduplatt@gmail.com,mar30hernandez@gmail.com \\ Universidad Nacional de la Patagonia Austral. Unidad Académica Caleta Olivia
}

Recibido: 01/07/2019. Aceptado: 09/12/2019

\section{RESUMEN}

En Argentina, el reconocimiento constitucional al patrimonio cultural lo ha colocado en un lugar privilegiado de tutela con responsabilidades para el Estado y los ciudadanos. A partir de la valoración de sus atributos como derecho colectivo, recurso cultural e identitario vinculado a la calidad de vida, factor dinamizador de las economías locales y generador de nuevos ingresos, los gobiernos locales están obligados a diseñar políticas patrimoniales no sólo que garanticen el ejercicio de los derechos culturales sino también que fomenten la preservación del patrimonio mediante la participación de los individuos, las comunidades o las ONGs reconocida en Pactos, Convenios y Protocolos ratificados por el Estado argentino. La Provincia de Santa Cruz ha generado políticas públicas para preservar el patrimonio cultural que interesa analizar desde un enfoque de derechos humanos.

Como propuesta metodológica se utilizan los tres tipos de indicadores de progreso (estructurales, de proceso y de resultado) en materia de Derechos Económicos, Sociales y Culturales (DESC) que propuso la Comisión Interamericana de Derechos Humanos (CIDH, 2008) y que permiten organizar la información relevada facilitando el análisis de las acciones estatales para el cumplimiento del derecho. Para indagar en las opiniones de los actores locales se realizaron encuestas y entrevistas en profundidad en las localidades de Puerto Deseado y Río Gallegos.

Palabras clave: participación; preservación; patrimonio cultural; derechos; calidad de vida.

\begin{abstract}
In Argentina, the constitutional recognition of cultural heritage has placed it in a privileged place of guardianship with responsibilities for the State and citizens. Based on the evaluation of its attributes as a collective right, cultural resource and identity element linked to the quality of life, a factor that stimulates local economies and generates new income, local governments are obliged to design heritage policies that not only guarantee the exercise of
\end{abstract}


cultural rights but also promote the preservation of heritage through the participation of individuals, communities or NGOs recognized in Covenants, Agreements and Protocols ratified by the Argentine State. The Province of Santa Cruz has generated public policies to preserve the cultural heritage, which are interesting to analyze from a human rights perspective.

As a methodological proposal, the three types of progress indicators (structural, progress and result) in ESCR issues proposed by the Inter-American Commission on Human Rights (ICHR, 2008) are used, which allow organizing the information collected and facilitates the analysis of State action with regards to the fulfillment of the right. In order to investigate the opinions of the local actors, surveys and in-depth interviews were conducted in the cities of Puerto Deseado and Río Gallegos.

Key words: participation; preservation; cultural heritage; rights; quality of life.

\section{INTRODUCCIÓN}

Con la inclusión de los "nuevos derechos" la Constitución Nacional busca reafirmar la participación ciudadana y la descentralización estatal que encuentran en el ámbito local el espacio más adecuado para un desarrollo conjunto respecto de actividades tendientes a una mejora en la calidad de vida, en concordancia con el Objetivo de Desarrollo Sustentable $\mathrm{N}^{\circ} 11$ que alude a las ciudades y comunidades sostenibles y a la salvaguarda del patrimonio cultural y natural del mundo (meta 11.4). Esto significa que son los habitantes de las ciudades y sus gobernantes quienes deberían diagramar propuestas y ejecutar acciones frente a los problemas relacionados con el entorno inmediato para lo cual es esencial que puedan participar.

La preocupación por la preservación del patrimonio se relaciona con sus atributos (mejora la calidad de vida, fortalece las identidades socio-territoriales, genera recursos locales, conecta a las comunidades intergeneracionalmente) que lo han convertido en un bien colectivo protegido por el art. 41 de la Constitución Nacional argentina.

Con rango constitucional, el Estado también incluyó el Pacto Internacional de Derechos Económicos, Sociales y Culturales (PIDESC) asumiendo el compromiso de garantizar el ejercicio de los derechos que en él se enunciaban y que busca su efectivización a través del Protocolo Adicional a la Convención Americana sobre Derechos Humanos en materia de DESC o "Protocolo de San Salvador" (OEA, ratificado por Argentina en 2003). Este último constituye un mandato para los Estados y provee de garantías para los ciudadanos, dado su carácter vinculante, en el marco del sistema interamericano de derechos humanos. Específicamente dedica el art. 14 inc. 1 a la participación en la vida cultural colocando en cabeza de las comunidades una responsabilidad fundamental en la promoción de los derechos culturales de toda persona a nivel local y nacional, así como en la cooperación con los Estados parte. Este ejercicio de los derechos culturales puede realizarse de tres modos a) individualmente; b) en asociación con otros; o c) dentro de una comunidad o un grupo.

Interesa, entonces, analizar la noción participación reconocida en la normativa vigente tanto a nivel internacional (Pactos, Convenios, Protocolos) como nacional aplicable a la preservación del patrimonio cultural material e inmaterial que ha sido receptada por la legislación patrimonial de la Provincia de Santa Cruz. Para ello se analiza la Convención para la Salvaguardia del patrimonio cultural inmaterial (UNESCO, 2003), la Observación general No 
21 del Comité PIDESC del año 2009 y las Directrices Operativas de la Convención para la Salvaguardia del patrimonio cultural inmaterial en lo referido a la noción de participación. Todos ellos son instrumentos, algunos de carácter vinculante y otro interpretativo, que forman parte del sistema jurídico argentino y que cobran efectividad a partir de la formulación de políticas públicas que el Estado argentino ha generado para preservar el patrimonio cultural. El objetivo del proyecto fue analizar las políticas públicas que la Provincia de Santa Cruz ha generado para preservar el patrimonio cultural puntualizando en la descripción de los mecanismos de acceso a la participación previstos por el ordenamiento jurídico provincial y municipal. Asimismo, se han identificado los actores estatales y no estatales que participan en las ciudades de Río Gallegos y Puerto Deseado comparando sus modalidades de participación en los procesos de detección y selección de bienes patrimoniales.

\section{MARCOS DE REFERENCIA}

\section{Marco histórico}

El artículo forma parte de los debates generados en el Proyecto de Investigación 29/B235 "Políticas públicas para la preservación del patrimonio cultural. La participación como derecho en la normativa provincial y municipal de Santa Cruz (2010-2018)", dirigido por la Dra. Graciela Ciselli, que forma parte del Programa de Políticas Públicas Sociales aprobado por Resolución 238/18 R-UNPA en el marco del Programa de Apoyo al Fortalecimiento de la Ciencia y Técnica en las Universidades Nacionales desde la Secretaría de Políticas Universitarias de la Nación. El área de Derechos Humanos se encuentra entre las líneas consideradas para responder a las demandas de la población cuando se trata de situaciones vinculadas al derecho de participación en la vida cultural y que aplica específicamente al caso bajo estudio de la preservación del patrimonio cultural.

Dado que el proyecto forma parte de este Programa, la directora y uno de los integrantes de este equipo participaron previamente de cuatro talleres de Políticas Públicas Sociales que contaron con el asesoramiento de la Dra. Laura Pautassi, el Dr. Gustavo Gamallo y la Mg. Lorena Ballardini pertenecientes al Grupo de Trabajo Interdisciplinario de Derechos Sociales y Políticas Públicas de la Universidad de Buenos Aires. Durante la ejecución del mismo se siguió participando de talleres vinculados a cuestiones metodológicas y de difusión de resultados.

Como antecedente en el tema a investigar, hemos abordado el patrimonio cultural desde diversas perspectivas desde el año 2006 promoviendo investigaciones, proyectos extensionistas y publicaciones que actualmente sirven como documentos de base para los estudios patrimoniales en Chubut y avanzar comparativamente con otras provincias, como es el caso de Santa Cruz (Ciselli, 2014 y 2018).

Desde el año 2012 hemos profundizado en el Patrimonio Industrial y en su relación con la normativa ambiental vigente. En la Cuenca del Golfo San Jorge, la actividad industrial relacionada con la explotación petrolífera y ferroviaria se encuentra estrechamente vinculada con la identidad local y regional (Ciselli y Hernández, 2014, 2017 y 2018). Es por ello que algunos de los temas que constituyeron los principales ejes abordados en los proyectos mencionados fueron los siguientes:

- Las identidades barriales en torno a dicho pasado industrial.

- La defensa de bienes culturales a través de las movilizaciones. 
- La valoración del patrimonio industrial como recurso turístico local.

Asimismo, se vincula con el PI 29/B226 "La protección de los derechos colectivos y la participación en la vida cultural" que hemos venido desarrollando desde el año 2017 y con la formalización de la RED UNPA El patrimonio cultural: miradas interdisciplinarias (Acuerdo 216 /2018 UNPA-UACO) que reúne a cinco equipos de investigación de universidades públicas (UNPSJB, UNMdP, UNC y UAdER). La conformación de la Red pretende aportar a la reflexión teórica conjunta y a la articulación de proyectos con la ciudadanía en torno a la preservación del patrimonio cultural, tal como se ha promovido con el dictado del Seminario taller "La preservación del patrimonio cultural. El marco legal nacional y provincial y su aplicabilidad al caso local" y con la participación en el Coloquio "Memoria, Patrimonio Cultural y Oralidad en Patagonia" con actores del patrimonio cultural regional dentro de las Jornadas $10^{\circ}$ Aniversario Área de Patrimonio Cultural Regional realizadas en noviembre de 2018 en la UACO. A ello se sumó la co-coordinación del Taller "Herramientas legales para fomentar la participación de las comunidades en la protección del patrimonio cultural" en el marco del Simposio Científico "Patrimonio Cultural y Desarrollo Sustentable" realizado en La Plata en diciembre de 2018 organizado por ICOMOS.

Como actividad pendiente de realización para septiembre de 2019 está la coordinación de la mesa temática 1: "El patrimonio industrial y su gestión. Desafíos para las comunidades locales" en el II Seminario Internacional de Patrimonio Cultural. Comunidades, gestión y protección a realizarse los días 19 y 20 de septiembre de 2019 en la sede de la UAdER (Paraná, Entre Ríos) organizado como una actividad conjunta de la RED UNPA.

\section{Marco teórico conceptual}

La noción de patrimonio cultural ha logrado consolidarse desde de la Segunda Guerra Mundial tanto desde un punto de vista técnico - que incluye inventarios y prácticas de intervención y gestión de los corpus patrimoniales- como institucional- normativo.

Hasta mediados de siglo XX el concepto "Patrimonio Cultural" estuvo fuertemente asociado a la protección de bienes culturales tangibles de la cultura europea y en el siglo XXI fue ampliado a los bienes culturales intangibles con la "Convención para la salvaguardia del patrimonio cultural" (París, 2003) y la "Convención sobre la protección y la promoción de la diversidad de las expresiones culturales" (París, 2005). El patrimonio cultural, en todos los casos, supone una red compleja de relaciones con otros elementos.

La defensa del patrimonio no solo se vincula con la calidad de vida como compromiso intergeneracional sino también con las identidades sociales que emergen cuando, por ejemplo, los residentes de un barrio se identifican con ese microterritorio dentro de la macro unidad que constituye la ciudad, lo ponen en valor y se diferencian respecto del resto (Gravano, 2013). Es así que cobra valor como recurso cultural y turístico. Al tratarse de un recurso cuyos bienes son únicos y que pueden generar rentas a partir de los servicios derivados de él, el Estado tiene la obligación de su regulación, protección y financiamiento. Es decir que tanto el valor cultural como económico justifican su tutela. El desafío está en descubrir si es patrimonializable o no en términos de lo que significa para determinada comunidad. 
Los cambios que se han producido en las últimas tres décadas ${ }^{1}$ en la forma de abordaje del Patrimonio Cultural se relacionan con desarrollos teóricos -donde se lo discute como herencia, construcción ideológica, sistema de representación- y con procesos más amplios que involucran la actuación de organismos internacionales a través de la generación del soft law. Esta normativa blanda puede ser considerada fuente por su uso entre los expertos, dado que contiene reglas de conducta que son observadas como referencia o aceptadas por los sujetos interesados, e incluso porque han sido admitidas en algunos tribunales.

Argentina no ha sido ajena a estos procesos. La Constitución Nacional reformada en 1994 al incorporar tratados internacionales de derechos humanos ha consagrado los derechos colectivos convirtiéndose en el marco normativo para la preservación del patrimonio cultural. Es decir, que se trata de un derecho que debe ser incluido en el diseño y la implementación de políticas públicas tanto a nivel nacional como local (Abramovich y Pautassi, 2009), efectivizado por parte de los Estados y garantizado a los ciudadanos.

Los Estados parte tienen además la obligación de "Respetar y proteger el patrimonio cultural en todas sus formas", "Promulgar legislación adecuada, establecer mecanismos efectivos que permitan a las personas, -individualmente, en asociación con otros o dentro de una comunidad o grupo-, participar efectivamente en los procesos de adopción de decisiones, (...) reclamar y obtener una indemnización si se han infringido sus derechos". Este último aspecto se conecta con la legitimación amplia prevista en el art. 43 de la Constitución Nacional para actuar en defensa de los bienes colectivos fundamentado en los atributos que estos poseen.

Así aparece la noción de participación en las normas cuando se reconoce que la plena realización del derecho de toda persona a participar en la vida cultural requiere de la disponibilidad para su disfrute y la accesibilidad a la información.

En 2009, el Comité de Derechos Económicos, Sociales y Culturales de las Naciones Unidas emitió la Observación General No 21 como guía interpretativa de la noción "participar" o "tomar parte" en la vida cultural reconocida en el artículo 15 inciso 1.a) del PIDESC y en el artículo 14 inc. 1 del PSS.

El ejercicio de los derechos culturales (aplicable al patrimonio cultural) puede realizarse de tres modos que han sido reconocidos por el Comité PIDESC y desarrollado en esta Observación General:

a) individualmente

b) en asociación con otros

c) dentro de una comunidad o un grupo.

El Comité sostiene que la participación es uno de los tres modos y generalmente se encuentra interrelacionado tanto con la posibilidad de creación artística como de compromiso político (que puede leerse en nuestro caso como participación ciudadana en sentido amplio):

a) la participación en la vida cultural;

1 La década del noventa sintetiza gran parte de las discusiones que fueron apareciendo a lo largo del siglo XX. Desde la Carta de Washington (1987), las ciudades son pensadas como espacios vitales que deben rehabilitarse no sólo desde un punto de vista material sino también simbólico. Como herramienta para la apreciación y comprensión de los sitios culturales patrimoniales por parte del público se proponen diversas actividades contenidas en la noción de interpretación tal como se analiza en la Carta de Quebec 2008. 
b) el acceso a la vida cultural, es decir, "beneficiarse del patrimonio cultural y de las creaciones de otros individuos y comunidades", aparece como una dimensión pasiva de la participación.

c) la contribución a la vida cultural, "a participar en el desarrollo de la comunidad a la que pertenece, así como en la definición, formulación y aplicación de políticas y decisiones que incidan en el ejercicio de sus derechos culturales".

Relacionado con los incisos a y c que remarcan la dimensión activa cuando se trata del ejercicio de los derechos culturales, la Convención para la Salvaguardia de Patrimonio Cultural Inmaterial del año 2003, ratificada por Argentina en 2006 (incluidas sus Directrices Operativas del año 2008), reconoce la importancia de la participación "de las comunidades, los grupos y, si procede, los individuos, así como de los expertos, los centros de competencias y los institutos de investigación" (Capítulo III de las DO) y también de las Organizaciones no gubernamentales (ONGs) a nivel nacional, alentando a los Estados Parte a "establecer una cooperación funcional y complementaria entre quienes crean, mantienen y transmiten el patrimonio cultural inmaterial, así como entre los expertos, centros de competencias e institutos de investigación". Esa participación es clave en a) la identificación y definición de los distintos elementos del patrimonio cultural inmaterial presentes en su territorio; b) la confección de inventarios; c) la elaboración y ejecución de los programas, proyectos y actividades; d) la preparación de los expedientes de candidatura para la inscripción en las Listas e) la exclusión de un elemento del patrimonio cultural inmaterial de una Lista o su traspaso a la otra. Este análisis excede los límites de este artículo, por lo que se hace esta breve mención de ello ya que se ha tenido en cuenta el inciso a) en la encuesta realizada y ha sido un instrumento internacional considerado en el desarrollo del proyecto de investigación. En cuanto a la noción de ONG es planteada por la Organización de las Naciones Unidas ONU- como una "organización voluntaria de ciudadanos sin ánimo de lucro, nacional o internacional” o por la Organización para la Cooperación y el Desarrollo Económico OCDE - como "organización fundada y gobernada por un grupo de ciudadanos privados con un declarado propósito filantrópico, y sostenida por contribuciones individuales privadas" (Pérez Ortega y otros, 2011: 246). Es decir que son organizaciones de la sociedad civil, voluntarias, jurídicamente reconocidas, que actúan sin fines de lucro bajo el formato de fundaciones y asociaciones con el objetivo de aportar sus esfuerzos para satisfacer necesidades sociales y culturales.

Con sus acciones -marchas, panfletos, presentaciones, reclamos, peticiones- buscan fortalecer la democracia participativa. En ella aparecen dos componentes: uno que comprende los actos y acciones mismas de participación, es decir, el "hacer" de la sociedad civil mediante tareas educativas, de concientización de la opinión pública, de movilización social o cualquier otro tipo de involucramiento en las cuestiones públicas (ejemplo identificando elementos patrimoniales); y otro "institucional", referido al conjunto de instituciones que reconocen y garantizan el ejercicio de los derechos de la ciudadanía, por ejemplo, a asociarse, a peticionar ante las autoridades, a acceder a la información pública, etc. (Ryan, 2001). Asimismo, presionan con sus acciones para que los recursos públicos y privados sean destinados a proyectos de desarrollo y a actividades de sensibilización y educación.

En Argentina a las organizaciones sin fines de lucro se las denomina de diversas maneras: entidades de bien público, organizaciones benéficas, organizaciones no gubernamentales 
(ONG), organizaciones sociales, organizaciones de la sociedad civil (OSC), entidades intermedias, organizaciones del tercer sector, organizaciones comunitarias. En ocasiones, se las menciona haciendo referencia a su forma jurídica: asociaciones civiles, fundaciones o mutuales (Roitter y Gonzalez Bombal, 2000: 10). Una aclaración que los autores realizan es que hay que diferenciar el apelativo "sin fines de lucro" de su rol específico en la sociedad. Se trata de instituciones no lucrativas -no porque sus servicios sean gratuitos- sino porque no distribuyen sus excedentes entre sus directores o miembros bajo la forma de ganancia. La otra es que por la sola asociación no se logra el objetivo de por ejemplo mejorar la calidad de vida si "el Estado carece de capacidad para representar los intereses del conjunto y si las empresas... no asumen la responsabilidad que las comunidades en las que están insertas comienzan a demandar" (Roitter y Gonzalez Bombal, 2000:11).

Si bien el punto de diferenciación es que son sin fines de lucro también se clasifican según su objetivo, si están jurídicamente reconocidas y si existen diferencias en el modo en que se relacionan con el entorno. En este caso pueden delimitarse dos grupos de organizaciones: las comunitarias que trabajan para el espacio público brindando servicios intangibles o las organizaciones de base que lo hacen en programas de desarrollo comunitario y de promoción social (ej. mejoramiento de barrios) y las de membresía, que brindan servicios a sus miembros o asociados a cambio del pago de una cuota u arancel (clubes, asociaciones de profesionales, sindicatos, grupos de afinidad). Pinzón Camargo (2005) plantea que pueden dividirse en ONGD y en ONGH según sus acciones específicas: el primer grupo orientado a labores relacionadas con el desarrollo y el segundo con la protección de los derechos humanos.

En cualquiera de los casos asesoran, informan, vigilan las acciones de actores estatales y privados incidiendo sobre ellos, realizan tareas vinculadas a la ayuda humanitaria, la prevención de conflictos, la cooperación al desarrollo y la prestación de ciertos servicios sociales públicos. La sociedad civil es el agente que puede potenciar los recursos culturales mediante la sensibilización acerca de su significación para un mejoramiento de la calidad de vida de los habitantes sin olvidar que en cada proceso de definición y apropiación patrimonial se conjugan diversos factores: contingentes, o sea, referidos al contexto socio político del momento; heredados, es decir, asociados a la historia del grupo y a su memoria social; normativos, vinculados a reglas y convenciones sociales y sociales que expresan la posición de los actores en la estructura social y su disposición de recursos.

\section{Recepción del derecho: El lugar otorgado a las comunidades en la legislación internacional del patrimonio cultural material e inmaterial}

El derecho a participar en la vida cultural (DPVC), y a los beneficios de la cultura, como un derecho humano si bien estuvo contemplado en la Declaración Universal y en la Declaración Americana de los Derechos y los Deberes del Hombre de 1948 y en el Pacto Internacional de Derechos Económicos, Sociales y Culturales (PIDESC) de 1966, ha tardado casi medio siglo en desarrollarse en el marco del Derecho Internacional de los Derechos Humanos.

Los instrumentos mencionados contemplan la participación en la vida cultural de las personas. La Declaración Universal de Derechos Humanos (1948) en su art. 27 inc 1. Expone que "Toda persona tiene derecho a tomar parte libremente en la vida cultural de la comunidad (...)". 


\begin{tabular}{|c|c|c|c|c|}
\hline Normativa & $\begin{array}{l}\text { Año de } \\
\text { sanción/ } \\
\text { En } \\
\text { vigor }\end{array}$ & $\begin{array}{l}\text { Ratificación } \\
\text { por } \\
\text { Argentina }\end{array}$ & Artículo & Derecho contemplado \\
\hline $\begin{array}{l}\text { Declaración Americana de } \\
\text { Derechos y Deberes del Hombre } \\
\text { y Declaración Universal de los } \\
\text { DDHH }\end{array}$ & 1948 & 1948 & $\begin{array}{c}13 \\
27.1\end{array}$ & $\begin{array}{l}\text { Toda persona tiene derecho a } \\
\text { tomar parte libremente en la vida } \\
\text { cultural de la comunidad }\end{array}$ \\
\hline PIDESC & $\begin{array}{l}1966 \\
1976\end{array}$ & 1986 & 15.a & $\begin{array}{l}\text { El derecho de toda persona a } \\
\text { participar en la vida cultural }\end{array}$ \\
\hline $\begin{array}{l}\text { Protocolo Adicional PIDESC o } \\
\text { Protocolo de San Salvador }\end{array}$ & $\begin{array}{l}1988 \\
1999\end{array}$ & 2003 & 14.1.a & $\begin{array}{l}\text { El derecho de toda persona a } \\
\text { participar en la vida cultural y } \\
\text { artística de la comunidad }\end{array}$ \\
\hline $\begin{array}{l}\text { Convenio } \mathrm{N}^{\circ} 169 \text { sobre Pueblos } \\
\text { Indígenas y Tribales (OIT) }\end{array}$ & $\begin{array}{l}1989 \\
2000\end{array}$ & 2000 & $\begin{array}{c}6 \\
19 \\
\end{array}$ & Participación y consulta \\
\hline $\begin{array}{l}\text { Convención para la } \\
\text { del Salvaguarda } \\
\text { Inmaterial (PCI) }\end{array}$ & $\begin{array}{l}2003 \\
2006\end{array}$ & 2006 & 15 & $\begin{array}{l}\text { Participación de comunidades, } \\
\text { grupos e individuos }\end{array}$ \\
\hline Protocolo Facultativo PIDESC & $\begin{array}{l}2008 \\
2013\end{array}$ & 2011 & -- & $\begin{array}{l}\text { Designación de Comité. } \\
\text { Elaboración de Observaciones }\end{array}$ \\
\hline
\end{tabular}

El Estado argentino, primero con la ratificación y luego con la Reforma Constitucional de 1994, invistió de jerarquía constitucional a aquellos instrumentos internacionales relacionados con los derechos humanos, los que son enumerados taxativamente en su artículo 75 inciso 22 (Tabla 2).

Por otro lado, otorgó rango constitucional al patrimonio cultural en el artículo 41 obligando a todos (autoridades del Estado y comunidad) a preservarlo y reconoció a las autonomías municipales en su art. 123. Estos tres artículos y derechos deben ser interpretados en conjunto cuando se trata de la preservación del patrimonio cultural en tanto constituye un recurso vinculado a la calidad de vida de las comunidades, a la construcción de sus identidades socioterritoriales y un potencial elemento para el desarrollo local.

En 1976 la aprobación por la UNESCO de la Recomendación relativa a la participación y la contribución del pueblo en la vida cultural constituye un nuevo instrumento normativo internacional, a la vez que destaca que "la cultura no se limita al acceso a las obras de arte y a las humanidades sino que es a la vez adquisición de conocimientos, exigencia de un modo de vida, necesidad de comunicación", prescribiendo un conjunto de medidas, tanto legislativas y reglamentarias como técnicas, administrativas, económicas y financieras que deben cumplir las autoridades estatales con el fin de que todos los individuos puedan ejercitar libremente su derecho a la cultura, en el marco de su doble dimensión: la de acceder y gozar (papel pasivo) y la de tomar parte, crear y contribuir (papel activo) (Harvey, 2008).

El Pacto Internacional de Derechos Económicos, Sociales y Culturales (PIDESC) es un tratado internacional de derechos humanos que crea obligaciones internacionales legalmente vinculantes para los Estados que han aceptado sus estándares y que en la actualidad asciende a $168^{2}$. Argentina lo ratificó en el año 1986 y posteriormente lo incluyó al ordenamiento

2 Aunque el Estado argentino no hizo comentarios sobre el PIDESC, la ratificación de los tratados, las declaraciones, las reservas y las objeciones planteadas por los Estados pueden consultarse en 
jurídico con rango constitucional en la Reforma de 1994 en el artículo 75 inciso 22. Al hacerlo asumió el compromiso de garantizar el ejercicio de los derechos que en él se enuncian. En el año 2003 Argentina ratificó el Protocolo Adicional a la Convención Americana sobre Derechos Humanos en materia de DESC o "Protocolo de San Salvador" que representa un mandato de efectivización de esos derechos para los Estados y de garantías para los ciudadanos. Este instrumento jurídico es de carácter vinculante para la defensa de los derechos culturales de los ciudadanos en el marco del sistema interamericano de derechos humanos.

El PIDESC en su artículo 15 inc. A, el Protocolo Adicional a la Convención Americana sobre Derechos Humanos en materia de DESC o "Protocolo de San Salvador" en el artículo 14 y la Observación general No 21 del Comité PIDESC del año 2009 contemplan el "Derecho de toda persona a participar en la vida cultural".

El artículo 14 del Protocolo, al referirse a las obligaciones de los Estados partes, reconoce tres derechos: "el derecho de toda persona a: a. Participar en la vida cultural y artística de la comunidad; b. gozar de los beneficios del progreso científico y tecnológico y c. beneficiarse de la protección de los intereses morales y materiales por ser autor de producciones científicas literarias y artísticas". En referencia a las obligaciones de actores que no son Estados, el PIDESC coloca en cabeza de las comunidades y las asociaciones culturales una responsabilidad fundamental en la promoción del derecho de toda persona a participar en la vida cultural a nivel local y nacional, así como en la cooperación con los Estados partes.

Asimismo, el PIDESC (1966) en su art. 15 inc a. dispone que los Estados parte "reconocen el derecho de toda persona a participar en la vida cultural". Esto se relaciona con la Convención para la Salvaguardia del Patrimonio Cultural Inmaterial (2003) en cuanto a que su art. 2 última parte establece que "A los efectos de la presente Convención, se tendrá en cuenta únicamente el patrimonio cultural inmaterial que sea compatible con los instrumentos internacionales de derechos humanos existentes y con los imperativos de respeto mutuo entre comunidades, grupos e individuos y de desarrollo sostenible". Asimismo, dispone que los Estados aseguren la participación de las comunidades, los grupos y las ONGs pertinentes en la identificación y definición de los distintos elementos del patrimonio cultural inmaterial (art. 11 inc. b) y tratar de lograr una participación lo más amplia posible de las comunidades, los grupos y, si procede, los individuos que crean mantienen y transmiten ese patrimonio y de asociarlos activamente a la gestión del mismo (art. 15).

\section{El valor del soft law}

Más allá de los reconocimientos estatales es necesaria la verificación del cumplimiento de las obligaciones contraídas para lo cual se han desarrollado órganos de seguimiento y grupos de trabajo expertos y lo que se denomina soft law, es decir, recomendaciones y observaciones que constituyen las guías interpretativas para el cumplimiento de tales obligaciones (Tabla 3).

https://treaties.un.org/Pages/ViewDetails.aspx?src=TREATY\&mtdsg_no=IV-

$3 \&$ chapter $=4 \&$ clang=_en 


\begin{tabular}{|l|c|c|}
\hline \multicolumn{1}{|c|}{ Soft Law } & $\begin{array}{c}\text { Año de } \\
\text { elaboración }\end{array}$ & Derecho contemplado \\
\hline Directrices Operativas del PCI & 2008 & Participación \\
\hline Observación N ${ }^{\circ}$ 21. PIDESC & 2009 & Participar en la vida cultural \\
\hline $\begin{array}{l}\text { Relatoría especial en la esfera de los derechos } \\
\text { culturales }\end{array}$ & 2009 & Principios internacionales aplicables a la \\
\hline $\begin{array}{l}\text { Relatoría especial de las UN sobre la situación } \\
\text { de los derechos humanos y las libertades } \\
\text { fundamentales de los indígenas }\end{array}$ & 2009 & $\begin{array}{c}\text { Sistema de indicadores de progreso } \\
\text { 2do agrupamiento de derechos del PSS }\end{array}$ \\
\hline Grupo de Trabajo: Informes & 2010 & Derecho al patrimonio cultural y natural \\
\hline \multicolumn{1}{|c|}{ Objetivos de Desarrollo Sostenible } & 2013 & Fuente: elaboración propia en base a la \\
\hline
\end{tabular}

Tabla 3: Soft law: relación participación y patrimonio cultural. Fuente: elaboración propia en base a la normativa vigente y al soft law.

Las Directrices Operativas para la aplicación de la Convención de Patrimonio Cultural Inmaterial disponen que los Estados parte deben "establecer una cooperación funcional y complementaria entre las comunidades, los grupos y, si procede, los individuos que crean, mantienen y transmiten el patrimonio cultural inmaterial (...)" (párr. 79); "sensibilizar a las comunidades, los grupos $\mathrm{y}$, si procede, los individuos a la importancia y el valor de su patrimonio cultural inmaterial, así como de la Convención, para que los depositarios de ese patrimonio puedan beneficiarse plenamente de dicho instrumento normativo" (párr. 81) y; adoptar "medidas apropiadas para fortalecer las capacidades de las comunidades, los grupos y, si procede, los individuos" (párr. 82).

Estos instrumentos resaltan la importancia de la participación de las comunidades y las personas y les otorgan un rol prioritario ya que son ellas quienes identifican su patrimonio cultural, lo transmiten y gestionan. Por esa razón, debe existir una participación activa de las comunidades para la preservación del mismo; que los integrantes consientan el proceso de salvaguardia patrimonial y sean los protagonistas del mismo. Esto implica que el Estado, como principal responsable del cumplimiento y protección de los derechos culturales, debe cogestionar desde y con la comunidad, ya que estas últimas deben participar en las distintas etapas para la salvaguardia de su patrimonio y su posterior inscripción. El Estado es el encargado de la creación de organismos, la sensibilización y aumento de capacidades de las comunidades y la distribución de la información a las mismas. Es decir que el rol del Estado es clave en el diálogo con los actores involucrados con el patrimonio y que éstos tomen control de ese espacio de participación.

La comunidad debe ser la protagonista en el proceso patrimonial especialmente cuando se trata de PCI. En este caso "la relación entre el PCI y las comunidades es vinculante, o sea se definen mutuamente, partiendo de que son manifestaciones o expresiones culturales preexistentes a su activación patrimonial, por ende, reconocidas así por las comunidades, grupos y/o sujetos que las crean, producen, reproducen, circulan, transmiten" (Lacarrieu, 2018: 18).

Antes de la Convención la participación social estaba relacionada con la visibilidad de la comunidad, mediante la relación de los agentes institucionales y expertos con aquella, a través de la recopilación y descripción de las culturas realizadas; dependía de la legitimidad de los actores sociales comprometidos con determinadas expresiones culturales, estableciendo que la 
mera presencia de la comunidad era garantía de participación. Desde la ratificación de la Convención surgió una nueva dinámica vinculada a que las comunidades participen en todo el proceso, desde la confección del inventarios y planes de salvaguardia; el antropólogo debe intervenir como mediador/traductor, como experto y como herramienta de participación comunitaria con el fin de activar patrimonios en comunidades y evitar distorsiones para lo cual se deben emplear estrategias que contemplen a los participantes de la comunidad como sujetos activos que toman decisiones, administran y controlan sus propios recursos y patrimonio cultural.

Esta participación implica el consentimiento y el compromiso de las comunidades y la gestión de los elementos del PCI mediante un debate informado entre sus miembros respecto de las perspectivas y los intereses de las comunidades interesadas y demás actores. La comunidad es quien debe ser protagonista y la que debe consentir los procesos de inventarios, relevamientos, registros, presentar un expediente o cuando se organiza actividades de sensibilización vinculadas a su PCI. Esto significa que la comunidad es la que debe consentir si desea revelar información sobre su patrimonio a otros públicos mediante estas acciones y planes (Lacarrieu, 2018).

Ya se ha explicado el valor de la Observación General No 21 como guía interpretativa de la noción "participar" o "tomar parte" en la vida cultural desarrollada por el Comité de Derechos Económicos, Sociales y Culturales de las Naciones Unidas. Asimismo, se han destacado los roles cumplidos por las Relatoras especiales respecto de la situación de los diversos derechos humanos y de los Grupos de Trabajo que formularon los indicadores de progreso de los derechos que se están analizando.

En el año 2015 la Organización de Naciones Unidos aprobó la Agenda 2030 para lo cual los países miembros acordaron 17 Objetivos de Desarrollo Sostenible que serán considerados como metas a cumplir por los Estados. Referido a nuestro caso el Objetivo $\mathrm{N}^{\mathrm{o}} 11$ alude a las ciudades y comunidades sostenibles y a redoblar los esfuerzos para salvaguardar el patrimonio cultural y natural del mundo (meta 11.4) para lo cual se requiere del compromiso y del trabajo en conjunto de todos los actores estatales y de la sociedad civil en su identificación, gestión y preservación.

\section{La normativa provincial y municipal en Santa Cruz}

En Santa Cruz, la Constitución reformada en 1998 si bien no menciona explícitamente la preservación del patrimonio cultural, en su artículo 3 reconoce que "todos los habitantes de la Provincia de Santa Cruz gozarán en ella de los derechos y garantías que la Constitución Nacional otorga, los que serán asegurados por los poderes provinciales", que interpretado junto con la primera parte del artículo 6 "En ningún caso podrán las autoridades de la Provincia suspender la observancia de esta Constitución ni de la Nacional, ni la efectividad de las garantías y derechos establecidos en ambas..." y del artículo 44 "La Provincia, por ley especial, podrá intervenir en las actividades económicas para promover el bienestar económico y social...”.

Otros artículos vinculados a los aspectos patrimoniales son el 52 referido al dominio originario de los recursos naturales, el 104 inc. 4 cuando menciona que el Poder Legislativo debe "proveer lo conducente a la prosperidad de la provincia... al progreso de las ciencias y las artes, la instrucción, educación y cultura..." 
Si bien dedica el artículo 73 al derecho a un ambiente "adecuado" (de modo similar al artículo 41 de la Constitución Nacional) poniendo en cabeza del "Estado y los particulares" la obligación del "cuidado y a la preservación del medio ambiente, así como a una explotación racional de los recursos naturales, para que las actividades productivas satisfagan las necesidades presentes sin comprometer las de las generaciones futuras". En el capítulo dedicado al Régimen Municipal, plantea en el artículo 150 inciso 10 el municipio tendrá competencia para "velar por la preservación del patrimonio cultural, arquitectónico, arqueológico, histórico y natural". Es decir que pone en manos de los gobiernos locales la responsabilidad legislativa respecto al tema.

En la normativa de la Provincia de Santa Cruz referida a la protección del patrimonio cultural y natural, arquitectónico, urbano y rural Ley 3138 de 2010 y en las Ordenanzas de los municipios de Río Gallegos No 8043 de 2013 y de Puerto Deseado No 6716 de 2017 aparece como objetivo "crear los mecanismos de consulta/participación a la comunidad general en cuestión relativas al patrimonio cultural y natural". Como antecedente de las legislaciones municipales se encuentran los Informes Finales realizados por la Dra. Ana María Bóscolo (Convenio CFI-Provincia de Santa Cruz) de los años 2012 y 2014 titulados "Lineamientos y propuestas de ordenanzas municipales para la protección del patrimonio cultural y natural, arqueológico y paleontológico de la provincia de Santa Cruz" y "Elaboración de las ordenanzas municipales de protección del patrimonio cultural y natural, arqueológico y paleontológico de la Provincia de Santa Cruz". En Río Gallegos y en Puerto Deseado, el anteproyecto de la Dra. Bóscolo se convirtió en las Ordenanzas 8043 de 2013 y No 6716 de 2017 respectivamente. Ambas son objeto de nuestro análisis teniendo en cuenta que, a partir del reconocimiento constitucional de las autonomías municipales que ha convertido a los municipios en los responsables originarios de las políticas urbanas y de la producción de reglas jurídicas, éstos han sancionado normas relativas a la protección del patrimonio cultural y natural.

En el marco del Convenio mencionado, se realizó un Taller de Capacitación en Puerto Deseado (p. 81 del Informe Final de 2012) donde se planteó la necesidad de "reformular los mecanismos de gestión y participación ciudadana permitiendo la activa intervención de los involucrados acreditados legalmente para su aporte y debate técnico" y "convocar a las universidades nacionales y a organismos académicos a los fines de su participación y aportes científicos en esta materia". Tanto en Puerto Deseado como en Río Gallegos en el lineamiento 8 de la normativa municipal, quedaron como objetivos "definir mecanismos de participación ciudadana y publicidad de los actos de gobierno" y "prever la implementación legal y administrativa de la consulta a la comunidad y a las organizaciones intermedias en materia de protección del patrimonio cultural y ambiental, hasta su intervención con dictámenes no vinculantes en los casos que fuere menester" (p. 31 Informe final).

Previstos los mecanismos en la normativa, ¿han sido creados? ¿qué noción de participación se desprende de la normativa? ¿Cómo se garantiza la participación de los individuos, grupos o asociaciones no gubernamentales cuando se trata la detección y selección de un bien como patrimonio cultural en las ciudades de Río Gallegos y Puerto Deseado? ¿Las Ordenanzas municipales prevén procedimientos administrativos que permiten la participación ciudadana tanto para la detección y selección como para la activación del bien luego de la declaratoria? 
¿Las comunidades tienen acceso público a los Registros de Bienes patrimoniales, pueden proponerlos como parte de circuitos turísticos?

Si bien en la Ley provincial de patrimonio (de 2010) está prevista la consulta (dirigida más a los pueblos originarios, además de ser una noción que podría interpretarse a partir de lo planteado por el Convenio 169 de la O.I.T); en las ordenanzas municipales referidas a patrimonio cultural se menciona la participación, pero no la consulta. En las tres normas se encomienda a una Comisión del patrimonio cultural (nivel provincial), Comisión Honoraria u Honorífica (en Puerto Deseado), a funcionarios o administración municipales, colegios profesionales, organizaciones no gubernamentales o involucrados acreditados legalmente. En cada caso conviene clarificar qué se entiende por consulta o participación para lograr que se efectivicen los derechos culturales reconocidos constitucionalmente, relacionados con el patrimonio cultural como bien colectivo.

Una regla jurídica es que "ley posterior deroga ley anterior". La normativa anterior referida al patrimonio y que aparece como vigente es la ley 2472 de 1997, por lo cual corresponde interpretar que la ley 3138 implica una derogación tácita parcial de la anterior, ya que existen aspectos de la vieja ley que complementan la nueva. Ej. composición de la Comisión de patrimonio o inicio del trámite al habilitar a "cualquier ciudadano podrá solicitar la iniciación de un expediente para obtener la declaración de un bien como patrimonio cultural". En su art. 8 crea y define quienes integran la Comisión de patrimonio "un representante de la subsecretaria de cultura, un representante del municipio o comisión de fomento donde esté ubicado el bien, un director del museo provincial, un representante de las entidades universitarias y un representante de las asociaciones culturales" y puede asistirse de profesionales o técnicos de las disciplinas que correspondieren en cada caso.

Para el caso de Puerto Deseado, el artículo No 24 de la Ordenanza 6716/2017 crea la Comisión Honoraria de Defensa del Patrimonio Cultural, Histórico y Arquitectónico de la ciudad como organismo de asesoramiento técnico con competencia en materia de patrimonio y que estará constituido por "personalidades acreditadas, se dictará su propio reglamento interno de funcionamiento y sus miembros podrán pertenecer a asociaciones civiles creadas por ley, a ONGs y a la Municipalidad” con dictámenes de carácter vinculante.

\section{2. Resultados, análisis y discusión}

\section{Materiales y Método}

Como propuesta metodológica se utilizaron los tres tipos de indicadores de progreso ${ }^{3}$ en materia DESC que propuso la Comisión Interamericana de Derechos Humanos (CIDH, 2008) que permitieron organizar la información relevada facilitando el análisis de las acciones estatales para el cumplimiento del derecho. Los indicadores mencionados son:

- Los estructurales identifican qué medidas dispone el Estado para implementar los derechos comprometidos en el Protocolo de San Salvador. Para ello fue necesario relevar información acerca del aparato institucional y el sistema legal nacional, provincial y municipal.

3 Los indicadores son parámetros o unidad de medida de tipo cuantitativo que es necesario complementar con el análisis cualitativo. 
- Los de proceso buscan medir la calidad y magnitud de esfuerzos del Estado, en sus diversos niveles de gobierno para implementar los derechos a través de la medición de la cobertura y el contenido de estrategias, programas o políticas destinadas al logro de las metas. Son indicadores que ayudan a vigilar la aplicación de las políticas públicas.

- Los de resultado buscan medir el impacto efectivo de las estrategias e intervenciones del Estado o de esas acciones públicas sobre aquellos aspectos que definen el grado de efectividad de un derecho del Protocolo y proveen una medida cuantitativamente comprobable y comparable del accionar del Estado en la realización progresiva de los derechos.

La CIDH clasifica esos tres indicadores en tres categorías conceptuales que son: recepción del derecho en el sistema legal, las capacidades estatales para la satisfacción del derecho y el contexto financiero y compromiso presupuestario (cuánto le ha destinado del presupuesto oficial) y tres principios transversales: igualdad y no discriminación, acceso a la justicia y acceso a la información y participación. El más relevante es la capacidad estatal que implica analizar bajo que parámetros el Estado a través de sus diversos poderes (locales y regionales con sus respectivas capacidades técnicas, administrativas e institucionales) y con qué diseño institucional resuelve el conjunto de cuestiones socialmente problematizadas (Pautassi, 2010:78 y 79).

Para dar cuenta de los avances en el cumplimiento de los derechos del Protocolo de San Salvador (en nuestro proyecto, los culturales), el Estado debe elaborar informes para lo cual la información se ordena sobre la base del modelo compuesto por indicadores clasificados en las tres categorías conceptuales y tres principios transversales mencionados. Con esta herramienta se ha relevado la evidencia empírica correspondiente a cada uno de los indicadores, sus categorías y dos de los principios (Tabla 1) que permite medir el avance de los derechos culturales en la Provincia de Santa Cruz.

Las señales de progreso cualitativas también forman parte de la información requerida, no parten de categorías preestablecidas como es el caso de los indicadores, pero captan la perspectiva que los propios actores sociales tienen respecto a sus derechos. En este sentido, algunas de las preguntas del cuestionario cubrieron este aspecto particularmente en lo referido a la noción de participación y a la creación de organizaciones de la sociedad civil relacionadas con el tema patrimonial.

Dado que los indicadores de progreso utilizan información cuantitativa proveniente de estadísticas, encuestas, censos, etc. que facilitan el monitoreo de los derechos a partir de su medición y avance como parte de las políticas públicas, en este caso municipales, es que se ha diseñado una encuesta para ser utilizada como fuente de información aplicadas en las ciudades de Puerto Deseado y Río Gallegos. 


\begin{tabular}{|c|c|c|c|}
\hline \multirow{2}{*}{$\begin{array}{l}\text { Categorías } \\
\text { conceptuales }\end{array}$} & \multicolumn{3}{|c|}{ Indicadores de progreso } \\
\hline & Estructurales & De proceso & De resultado \\
\hline $\begin{array}{l}\text { Recepción del } \\
\text { derecho }\end{array}$ & $\begin{array}{l}\text { Ratificación estatal de } \\
\text { instrumentos internacionales } \\
(\text { desarrollados en cuadro } 2)\end{array}$ & $\begin{array}{l}\text { Existencia de acciones } \\
\text { relacionadas con temas } \\
\text { patrimoniales en los últimos } \\
\text { cinco años }\end{array}$ & $\begin{array}{l}\text { Cantidad de población } \\
\text { con acceso a programas } \\
\text { de promoción de } \\
\text { derechos culturales }\end{array}$ \\
\hline $\begin{array}{l}\text { Capacidad } \\
\text { estatal }\end{array}$ & $\begin{array}{l}\text { Existencia de una Secretaría } \\
\text { de Cultura, Inventarios y } \\
\text { Registros de Bienes culturales } \\
\text { accesibles }\end{array}$ & $\begin{array}{l}\text { Cantidad bienes y de áreas } \\
\text { protegidas declaradas en los } \\
\text { últimos cinco años }\end{array}$ & $\begin{array}{l}\text { Cantidad de videos } \\
\text { patrimoniales producidos } \\
\text { por entes estatales } \\
\text { Cantidad de museos } \\
\text { patrimoniales }\end{array}$ \\
\hline $\begin{array}{l}\text { Contexto } \\
\text { financiero y } \\
\text { compromiso } \\
\text { presupuestario }\end{array}$ & $\begin{array}{l}\text { Porcentaje de los } \\
\text { presupuestos provincial y } \\
\text { municipal destinado a las } \\
\text { Direcciones de PC } \\
\text { Existencia de incentivos } \\
\text { fiscales para el desarrollo de } \\
\text { derechos culturales }\end{array}$ & $\begin{array}{l}\text { Porcentaje de ejecución del } \\
\text { presupuesto asignado a cada } \\
\text { organismo } \\
\text { Porcentaje de transferen- } \\
\text { cias del Estado a grupos y } \\
\text { asociaciones pro defensa del } \\
\text { PC }\end{array}$ & 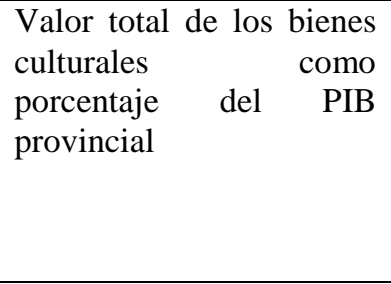 \\
\hline $\begin{array}{lr}\text { Principio } \\
\text { transversal } \\
\text { acceso a } & \text { la } \\
\text { información } & y \\
\text { participación } & \end{array}$ & $\begin{array}{l}\text { Existencia de un sistema de } \\
\text { divulgación del inventario de } \\
\text { bienes patrimoniales (portal, } \\
\text { prensa, radio, internet) }\end{array}$ & $\begin{array}{l}\text { Porcentaje de } \\
\text { empleados/funcionarios del } \\
\text { sector público que trabajan } \\
\text { en temas de PC } \\
\text { Jornadas pedagógicas de } \\
\text { sensibilización en PC } \\
\end{array}$ & $\begin{array}{l}\mathrm{N}^{\mathbf{o}} \text { de instancias de } \\
\text { participación abiertas } \\
\text { para selección de bienes } \\
\text { culturales } \\
\mathrm{N}^{\mathrm{o}} \text { de solicitud de datos } \\
\text { culturales }\end{array}$ \\
\hline $\begin{array}{l}\text { Igualdad y no } \\
\text { discriminación }\end{array}$ & $\begin{array}{l}\text { Existencia de mecanismos de } \\
\text { reconocimiento de patrimonio } \\
\text { cultural de pueblos } \\
\text { originarios }\end{array}$ & $\begin{array}{l}\text { Porcentaje de bienes } \\
\text { declarados de territorios } \\
\text { comunitarios con consulta } \\
\text { previa e informada }\end{array}$ & $\begin{array}{ll}\text { Cantidad de } & \text { población } \\
\text { participante } & \text { en las } \\
\text { declaratorias } & \end{array}$ \\
\hline
\end{tabular}

Como el objetivo era conocer la opinión de los encuestados respecto del patrimonio cultural para determinar el grado de información de la población de ambas ciudades, el acceso a la información relativa a los derechos culturales, la participación y el activismo de la sociedad civil en la identificación y selección de bienes culturales patrimonializables (señales de progreso cualitativas) se realizó una encuesta con un cuestionario que indagaba acerca de los bienes, lugares y objetos que consideraban representativos de cada ciudad, la producción de información por parte de los municipios que se relaciona con la difusión de las Ordenanzas y los mecanismos que promueven la participación comunitaria (indicadores de progreso).

Las encuestas estuvieron dirigidas al público en general y la clasificación si pertenecía al ámbito de la cultura o no se realizó en la etapa de procesamiento de los datos al abordar la variable ocupación. Dado que lo que se pretendía era indagar en la información y conocimiento que tuvieran los habitantes del tema patrimonio cultural y reconocimiento de elementos vinculados a dicha noción y de cómo entendían a la participación varias de las preguntas que se realizaron fueron abiertas.

En cuanto a su estructura, fueron divididas en tres partes: la primera para recabar las características socio-demográficas de la población (edad, género, estudios cursados, situación laboral, tiempo de residencia en la localidad), la segunda para indagar acerca de las siguientes dimensiones: definición de patrimonio cultural que incluye la selección que hacen los encuestados de objetos, edificios y lugares considerados representativos de cada ciudad y que deben ser protegidos, la recepción del derecho, capacidad estatal, acceso a la información y acceso a la participación y finalmente el control de la muestra (nombre del encuestador, lugar 
donde se realizó la encuesta, fecha y hora). En Puerto Deseado y Río Gallegos se hicieron 130 aplicando el mismo cuestionario.

Se consultaron otras fuentes secundarias que permitieron conocer acerca de las agendas culturales, la generación de nuevos espacios culturales, la existencia y creación de asociaciones civiles, la difusión del tema patrimonial en las instituciones escolares, en las bibliotecas, museos. Estos constituyen indicios del desarrollo de este derecho que, como se ha dicho, requiere de técnicas cuanti-cualitativas para recuperar la perspectiva de los actores involucrados. Dadas las características del derecho al patrimonio cultural se han realizado entrevistas en profundidad como técnica de investigación cualitativa y descripciones detalladas de algunos espacios culturales de reciente creación que forman parte del proceso de verificación empírica.

El último proceso está orientado a medir las acciones del Estado provincial y municipal que involucran las políticas públicas que se aplican a ejes transversales a todos los derechos como es el acceso a la información y a la participación.

\section{La capacidad estatal}

Esta categoría conceptual refiere al diseño institucional adoptado por el Estado para aplicar las normas. A nivel provincial y dependiente de la Secretaría de Estado de Cultura (Tabla 4), de la Dirección Provincial de Articulación y Promoción Cultural y de la Dirección General de Coordinación y Monitoreo funciona la Dirección de Patrimonio Cultural que tiene diversas áreas a su cargo: Arqueología, Paleontología, Capacitación, Tráfico Ilícito de Bienes Culturales y Arquitectura además de un cargo administrativo ocupado por la secretaria de la Dirección de Patrimonio Cultural.

En el Complejo Cultural funcionan el Archivo Histórico Provincial, la Dirección Provincial de Patrimonio, el Museo Regional Provincial "Padre Manuel Jesús Molina" y en otra área del Complejo se exhiben Artesanías Santacruceñas (PREPAP). Este espacio también cuenta con distintas muestras de arqueología y paleontología. 


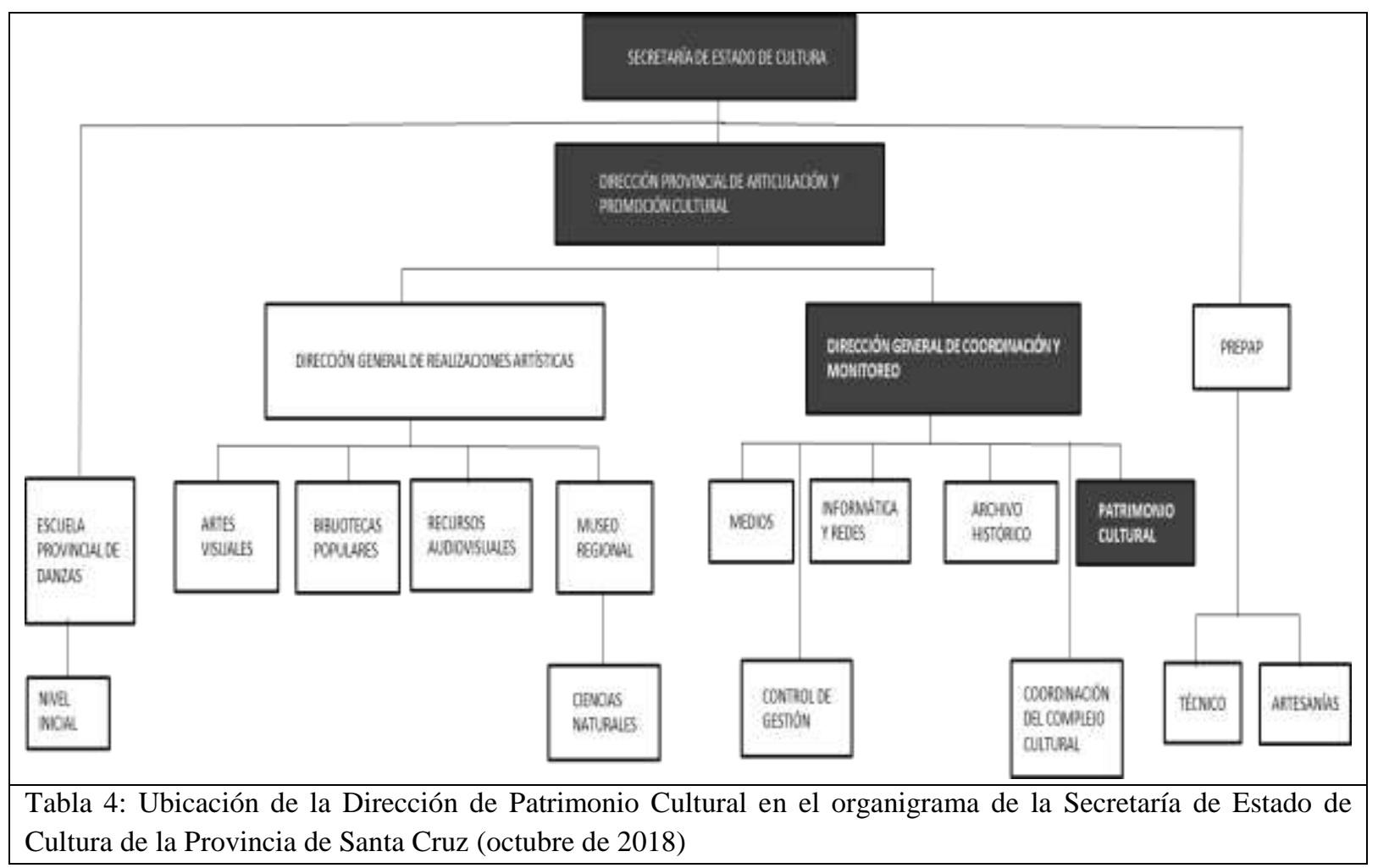

En Puerto Deseado lo vinculado al tema cultural depende de la Secretaría de gobierno de la Municipalidad", quien debe "promover la preservación y puesta en valor del patrimonio edilicio, urbanístico, paisajístico e histórico-cultural de nuestra ciudad y su comarca de influencia y fomentar el desarrollo cultural en todas sus manifestaciones e interactuar con las diversas organizaciones de la comunidad para fortalecer la identidad local y la preservación del patrimonio cultural". Esta Secretaría tiene a su cargo la Subsecretaría de Cultura y de esta dependen la Dirección de la Biblioteca Florentino Ameghino y la Dirección de Patrimonio y Museos. Esta última coordina a los Museos Mario Brozoski, el Museo Policlínico, el Museo Ferroviario y el Museo del Pueblo además del Archivo Histórico Municipal "Palmiro Pedemonte".

En la localidad la mayor parte de las declaratorias han sido provinciales, a excepción de la consideración del Puerto Deseado como sitio histórico propuesto por la Comisión Nacional (Tabla 5). En cuanto a las declaratorias provinciales corresponden a dos momentos distintos: uno centrada en el patrimonio natural del año 1977 que se amplía con la posibilidad de pensar en la creación de un Parque interjurisdiccional marino en 1992 y otro que cubre los años 2009 a 2011 que contempla la protección del ramal ferroviario desde Puerto Deseado a Las Heras y cada una de las estaciones de la línea en el contexto de los festejos a 90 años de la inauguración de dicha línea, un yacimiento arqueológico regulado por la Legislación de Patrimonio Arqueológico y Paleontológico y un sitio ubicado en una estancia de propiedad privada.

4 Puede consultarse en https://deseado.gob.ar/gobierno/organigrama/secretaria-de-gobierno/ 


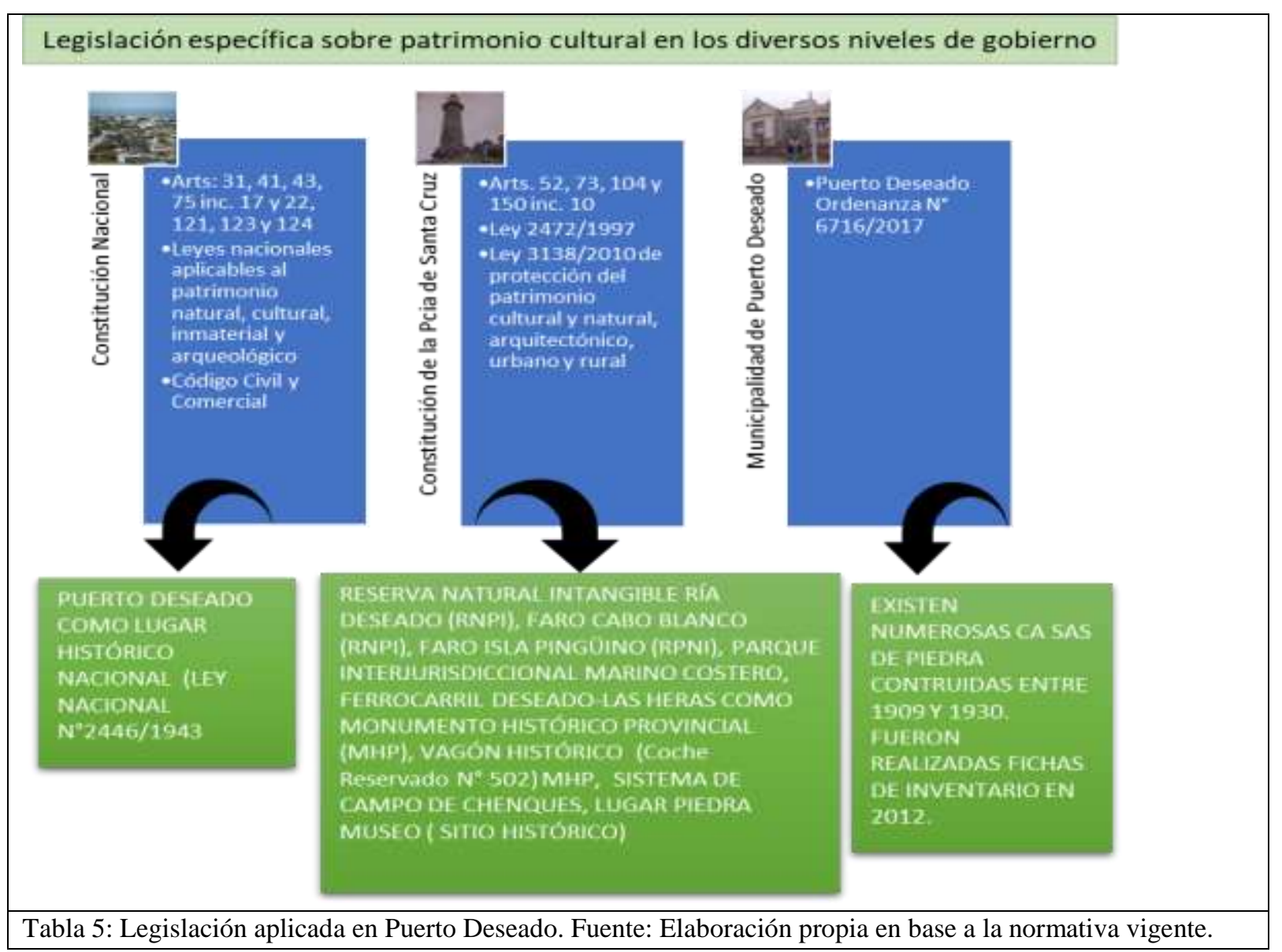

Aún no se cuenta con información para dar cuenta de los indicadores de proceso de la capacidad estatal, pero se presume que si no han sido incluidos en la Ordenanza de 2017 hasta esa fecha es que no existen otras declaratorias. Además de lo declarado, existen bienes inventariados (sin declarar) como las casas de piedra que aluden a un momento de la historia de Puerto Deseado vinculado a la construcción de la línea ferroviaria, que se inicia en 1909 y se paraliza en 1914, y a la llegada de obreros conocedores del trabajo en piedra. Es así que existen numerosas construcciones en este material obtenido en las proximidades de la localidad (la estación ferroviaria, casas de propiedad privada y pública, alcantarillas y tumbas en el cementerio local) durante un período que alcanza los inicios de los años 1930.

Como indicador de resultado de la capacidad estatal del municipio de Puerto Deseado se consideran la cantidad de museos con temas patrimoniales como evidencia cualitativa del avance en el interés y activismo de la comunidad por la puesta en valor de ciertos objetos vinculados a su historia. En la localidad son cuatro museos que datan de diferentes momentos y orígenes: tres son municipales y uno organizado por una asociación civil, la ferroviaria. El primero de ellos es el Museo Municipal Mario Brozoski, creado en el año 1983, con el objetivo de resguardar parte importante del patrimonio arqueológico que fue rescatado de la corbeta Swift, que se hundió en 1770 en la Ría. En dicho lugar existe un sector destinado a laboratorio donde se muestra el proceso de conservación y restauración de las piezas rescatadas e inventariadas.

Para conmemorar los noventa años de inauguración de la línea Deseado-Las Heras, en 1999, se organizó la Asociación Ferroviaria 20 de Septiembre con objetivos claros: dar a conocer la 
historia ferroviaria de la localidad. Proteger, aumentar en lo posible el patrimonio ferroviario y apoyar incondicionalmente todo proyecto posible para poner nuevamente en movimiento la línea ferroviaria Puerto Deseado-Colonia Las Heras. Este grupo de ex ferroviarios comenzó a trabajar activamente durante cuatro años para lograr abrir el Museo Ferroviario, que ocupa la estación ferroviaria y dar vida nuevamente a la Estación del Ferrocarril en el 2003. Ricardo Vázquez fue uno de los impulsores de la creación del Museo Ferroviario de Puerto Deseado. "La creación del museo nació con la imperiosa necesidad de conservar el lugar, luego de que fuera clausurada el 15 de enero de 1978... decidimos juntarnos ferroviarios, familiares y gente que se apasiona por los ferrocarriles para crear esta asociación que hoy vela por el mantenimiento de este lugar", señaló. En ese tiempo decidieron exhibir objetos que facilitó la comunidad, tales como: fotografías y otros elementos, algo que realmente tuvo una muy buena respuesta por parte de los vecinos que querían conocer más sobre este medio de transporte. Vinculado a la historia ferroviaria y a la memoria colectiva ha quedado el relato de una poblada que obstruyó la salida del camión que se llevaba el coche reservado 502 (hoy convertido en bien patrimonial) y tras diversas gestiones ante el Gobernador, finalmente fue declarado de interés provincial (Ciselli, 2001). El año 1980 es revivido como un momento dramático en la historia del pueblo en el cual dos instituciones, la Biblioteca y la Comisión de Amigos, tienen un rol activo cuando en el mes de diciembre defienden el "histórico vagón". En los discursos de los miembros de la Comisión de Amigos aparece como uno de sus máximos logros el haber conseguido que el gobernador de facto firmara la Ley 1573 decretando "La utilidad pública del reservado 502". El Archivo Histórico Municipal también funciona en la ex estación de ferrocarril que concentra gran parte de las actividades vinculadas a la cultura.

En 2017 habían transcurrido más de treinta años sin que el municipio abriera una Museo. Es así que para el aniversario del pueblo se inauguró el Museo Municipal Policlínico Ferroviario Dr. Juan Carlos Rostagno a metros del histórico Museo Ferroviario que había sido cerrado hace unos 27 años. Tras su fachada, producto de la arquitectura típica en roca que caracteriza a Puerto Deseado, puede descubrirse el funcionamiento del antiguo Policlínico Ferroviario a través de instrumental donado por el hijo del médico. Dicho edificio data del año 1909 cuando se dieron inicio a las obras del ferrocarril y fue la casa donde vivió el ingeniero Juan Briano, director de la construcción. En mayo de 1955 se fundó como Policlínico Ferroviario siendo destinado a cubrir los servicios médicos asistenciales, clínica médica, cirugía, obstetricia, pediatría y odontología. Carlota, la esposa de Rostagno, también fue una de las primeras médicas del lugar y una de las impulsoras de la creación de la Cooperadora del Hospital Distrital de Puerto Deseado, fundada en julio de 1968 y de la construcción del solario destinado para que los ancianos alojados en el hospital pudieran tomar sol, jugar a las cartas, y escuchar la radio en dicho sitio.

Entre los más recientes se encuentran el Museo del Pueblo inaugurado en 2018, en la ex Estación del Ferrocarril que contiene donaciones de vecinos y familias de la ciudad. Dividido en dos pisos, el primero destinado a la etapa fundacional y los primeros años de la localidad por lo que el énfasis está puesto en los objetos de la vida cotidiana, en la vida comercial entre los años 1920 a mediados de los cuarenta. En dicho espacio se prevén exposiciones itinerantes en dos de las salas para ir dinamizando el lugar con efemérides de la ciudad, de clubes y todo lo que refiere a la historia de Puerto Deseado. 
En Río Gallegos se creó la Comisión de Protección del Patrimonio Histórico Cultural Municipal por Ordenanza $N^{\circ}$ 2591/20045. Desde ese año, el municipio se mostró activo con la generación un Programa Municipal de Rescate para elaborar un inventario provincial de bienes $^{6}$, áreas protegidas urbanas de carácter municipal con sus reglamentaciones respectivas. La Comisión y el Centro de Investigación UNPA UARG organizaron un taller participativo en agosto de 2004 en el que participaron más de 70 vecinos para elaborar un primer listado de aquellos bienes culturales identitarios de la ciudad, en base a tres tipologías: lo arquitectónico, lo tangible no arquitectónico y los intangibles.

La Dirección de Gestión Cultural depende de la Secretaría de Desarrollo Humano. De la Dirección de Gestión Cultural dependen: Departamento Coordinación de Espacios Culturales (Casa Taller de Cerámica, CC Orkeke, CC Ravallo, Teatro Municipal, Biblioteca Municipal), Departamento Desarrollo Emprendedor (Club de Emprendedores), y Departamento Patrimonio Cultural (Museo de Los Pioneros, Archivo Histórico). Asimismo existen varios espacios de promoción y difusión cultural: Fundacruz (que expone arte local y nacional), Museo Eduardo Minnicelli (depende del CPE, fomenta arte local), Complejo Cultural Santa Cruz, NK Ateneo (café y espacio cultural), Casa Parisi - Museo de los Pioneros (depende de la Municipalidad), Museo Ferroviario (lo administra la Asociación Amigos del Tren Río Gallegos), Museo de Prefectura Naval, Museo de Guerra Malvinas Argentinas, Museo Marítimo y Naval de la Patagonia Austral, Casa Histórica Gregores, entre otros varios lugares ${ }^{7}$.

En referencia a las declaratorias patrimoniales corresponden a los tres niveles. Por un lado, existen las realizadas por la Comisión Nacional de Monumentos, de Lugares y Bienes Históricos (hasta el año 2015 denominada Comisión de Museos y de Monumentos y Lugares Históricos) y en su mayoría como Monumentos Históricos Nacionales (Balcón Roca en 1981, Iglesia Catedral Nuestra Señora de Lujan en 1985 y el antiguo edificio del Colegio María Auxiliadora en 2008), como Lugares Históricos Nacionales en la década del cuarenta ya había sido considerada la Desembocadura del Río Gallegos sobre margen derecha del Rio Gallegos.

Otro nivel de declaratoria fue el provincial que también declaró dos edificios escolares de gran significatividad para la sociedad riogalleguense ${ }^{8}$ (Escuela de artes y oficios en 1996 que también contó con declaratoria municipal y el Instituto María Auxiliadora en 2000), un objeto (muelle de madera del ex puerto carbonero en 1997) y el ramal ferro-industrial de Río Turbio a Río Gallegos vinculado a la exploración carbonífera fiscal.

5 Como antecedentes puede mencionarse la existencia de la Comisión Permanente de Conservación y Restablecimiento de Patrimonio histórico cultural de la comunidad por Ordenanza Municipal 1264/84 y Decreto 1426/84 y cuatro años después como medida preventiva de registro, se ordenó la elaboración de un archivo fotográfico y audiovisual del entorno paisajístico, cultural y arquitectónico susceptible de ser transformado, bajo la Ordenanza Municipal N²780/88 y Decreto $N^{\circ} 1973 / 88$. La actuación de esta comisión fue limitada.

6 En 2006 la Dirección del Patrimonio Cultural junto con el Consejo Federal de Inversiones elaboraron un Inventario del Patrimonio Urbano y Arquitectónico de la provincia que destacó 21 edificios representativos.

7 La recolección de esta información fue realizada por la Abog. Linda Mrázek.

8 Información relevada por Andriana Opacak y Susana Terzo (2018) Los riogalleguenses y el patrimonio arquitectónico especialmente para este proyecto. UNPA. UARG. 
A nivel municipal se realizaron la mayor cantidad de declaratorias relacionadas con diversos aspectos del patrimonio cultural. En algunos casos se privilegió la arquitectura de casas de chapa típicas de los inicios de la ciudad, la casa Parisi, que se estima fue construida a fines de siglo XIX por Greenshilds, Redman y Woodman, dueños de una sociedad ganadera y que en 1989 la municipalidad la convirtió en el Museo de los Pioneros. El Programa Rescate 1900 se inició en 2008 siendo aprobado por Decreto Municipal $N^{\circ} 1174 / 2009$ con el objetivo de difundir y valorar elementos de patrimonio tangible e intangible del siglo pasado inventariando patrimonio arquitectónico. En este marco, los edificios que fueron reconocidos por su valor arquitectónico por la Comisión municipal durante los años 2009 y 2011 fueron los siguientes: Casa Keoken construida en 1920 por el Frigorífico Swift hoy utilizado como Servicio Penitenciario Federal, el Colegio Británico de 1923, varias casas particulares de los años 1935, 1940 y 1950 y la ex barraca francesa de la empresa Segard y Cía refuncionalizada como restaurant.

\section{Contexto financiero y compromiso presupuestario}

La provincia de Santa Cruz tiene una Secretaría de Estado de Cultura que depende del Ministerio de Gobierno. Del Presupuesto provincial de 2018, Ley №3590, Decreto 427/18, aparece que, de un gasto total de 15.095.776.454,00 en transferencias corrientes, se destinaron 200.000 a transferencias de instituciones culturales y sociales en el Ministerio de Gobierno cuyo presupuesto era de 158.200.000 y que correspondía 50.301.366 a la Secretaría de Estado de Cultura.

El presupuesto provincial de 2018, si bien se encuentra publicado en el portal oficial, destina del total del Ministerio de Gobierno casi un 32\% a la Secretaría de Estado de Cultura, de los cuales destina el $94 \%$ a gastos de personal y un $6 \%$ puede ser utilizado para instituciones culturales y sociales sin fines de lucro. De esta fuente no se ha podido determinar los montos, si es que existen, destinados a la producción de información y a la difusión de la misma.

El presupuesto municipal de Río Gallegos no se encuentra disponible para la consulta pública.

En Puerto Deseado, existe la Sub Secretaría de Cultura que depende de la Secretaría de Gobierno. La Ordenanza N ${ }^{\circ}$ 6663-HCD-2016 del Honorable Concejo Deliberante, en su art. 1 surge que se estimó la suma de 497.986.642,72 destinados a la financiación del presupuesto general de gastos e inversiones de la Administración Central. Del presupuesto para el año 2017, aparece en el Anexo III que se destinarán 2.000.000 para Cultura en bienes y servicios no personales de un total de 25.710.000. Para el Plan de obras públicas Anexo IV, (p. 15), 60.000 para la Cultura, específicamente para el mantenimiento del Cine Teatro Español ${ }^{9}$. Es decir, que existe un porcentaje mínimo de transferencia del Estado para grupos o asociaciones pro defensa del patrimonio cultural.

9 Presupuesto de la Municipalidad de Puerto Deseado. 2017. Disponible en https://deseado.gob.ar/transparencia/presupuesto/presupuesto-2017/ 


\section{El acceso a la información como principio transversal desde la perspectiva de los encuestados}

En Puerto Deseado las encuestas se realizaron en tres lugares diferentes que se identificaron como en un domicilio particular, en la vía pública y en alguna institución u organización. Sólo 3 se realizaron en una vivienda familiar mientras que el resto de las encuestas se realizaron en la estación de servicio, en algunos comercios y confiterías, en la calle, en la biblioteca, en los museos, en el archivo histórico, en las escuelas y en las dependencias municipales relacionadas con el tema patrimonial. Es decir, que se considera que los lugares han sido diversos lo que ha permitido el acercamiento a personas de la localidad de distintas edades, género (que en su mayoría se definió como masculino o femenino).

En Río Gallegos, los principales lugares para encuestar fueron: edificios de la administración pública provincial, las tres entidades deportivas privadas principales de la ciudad y domicilios particulares de amigos. La vía pública no fue una opción por razones climáticas.

En referencia a la ocupación de los encuestados de Puerto Deseado (Gráfico 1), todos manifestaron realizar algún tipo de trabajo, a excepción de las dos estudiantes y un jubilado. Entre quienes trabajan en administración pública con relación al patrimonio cultural se han incluido los empleados de las direcciones de cultura y turismo, de los archivos, museos y bibliotecas públicas. Quienes han declarado formar parte del sistema educativo son todos docentes y directivos de las escuelas provinciales de la localidad o docentes de la UNPA y entre los que se dedican a la actividad privada se encuentran comerciantes, un escribano, un comunicador social, mozas de hoteles y confiterías y un trabajador de la empresa minera. Respecto de lo que mencionan trabajar en administración pública sin relación con el patrimonio se encuentran quienes son empleados municipales de otras áreas, del hospital y de Prefectura Naval.

Respecto de la edad, la más joven tiene 13 años y se encuentra cursando sus estudios secundarios. El mayor porcentaje de encuestados se ubica en el rango etario de mayores de 40 años quienes en su mayoría residen en la localidad algunos desde su nacimiento y otros con un mínimo de residencia de 20 años. La información obtenida referida a la edad fue cruzada con su conocimiento acerca del patrimonio cultural buscando responder ¿cuánto saben de patrimonio quienes tienen menos de 21 años de edad, los que se encuentran entre 20 y 40 y los que tienen más de 40 años? El tiempo de residencia en la localidad es una variable para identificar lugares o bienes representativos.

De los menores de 21 años, uno no contestó sobre qué entendía por patrimonio cultural, el segundo reconoció que era la primera vez que oía sobre el tema, el otro lo vinculó a reliquias antiguas y quien había tenido una materia sobre patrimonio en la escuela lo definió como los bienes tangibles e intangibles que las personas de una comunidad se sienten identificadas.

Entre los 20 y los 40, hubo 2 que no definieron patrimonio, el resto se divide en porcentajes similares apareciendo con fuerza la relación entre la representatividad del lugar o del edificio vinculado a la historia de la localidad y planteando que, aunque ese elemento del patrimonio esté descuidado debe ser defendido mediante la educación porque es una herramienta para hacer crecer a la ciudad. 


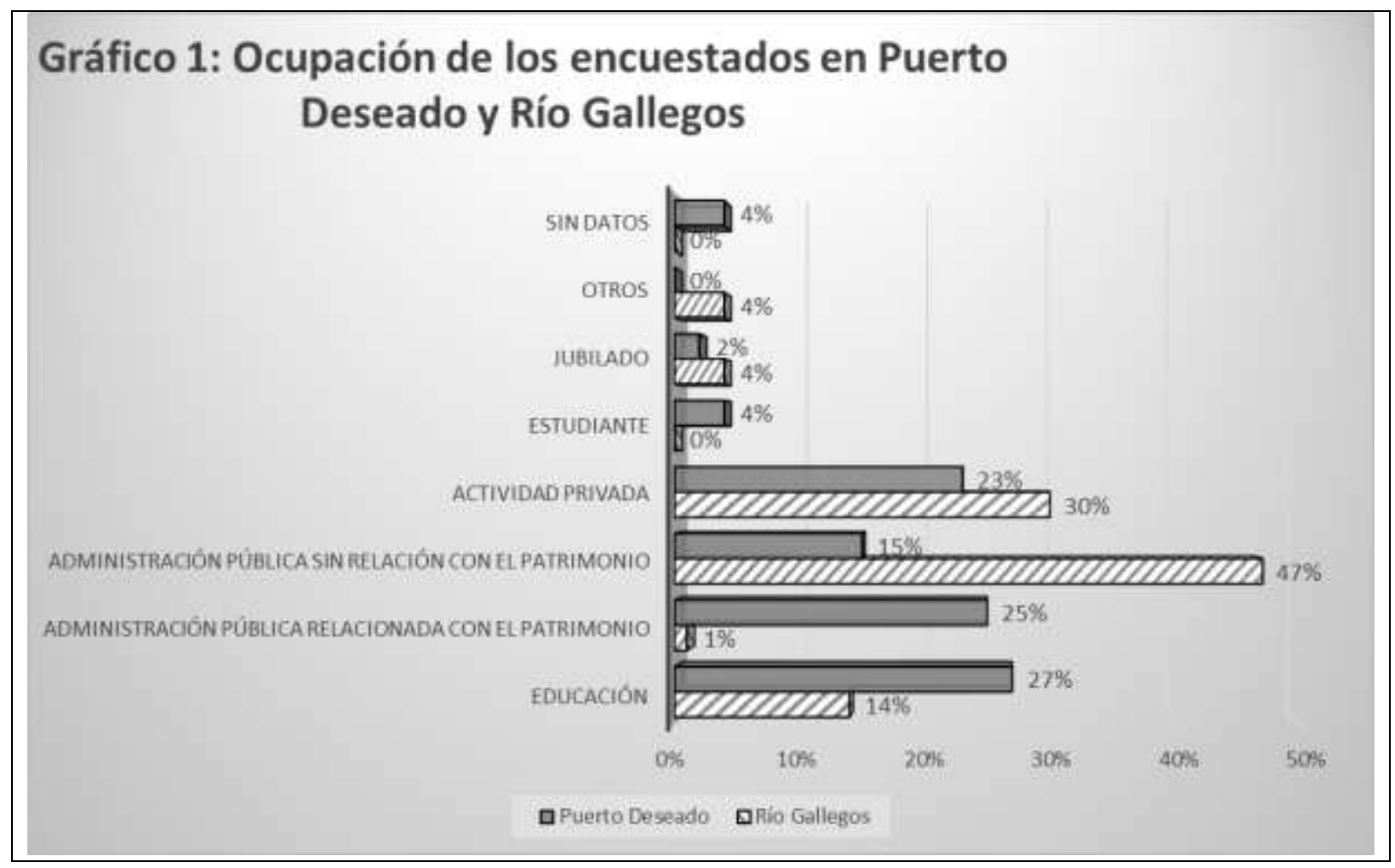

Los mayores de 40 años relacionaron el patrimonio cultural con la identidad, la historia viva de la comunidad, un legado histórico cultural determinante para todas las generaciones que debe ser resguardado porque es lo más preciado que nos queda como memoria de época pasadas y también es visto como una potencial herramienta turística. Es en este grupo donde aparece la noción con mayor precisión y quienes no tuvieron dificultad en identificar cinco lugares, objetos o edificios que consideran representativos de Puerto Deseado.

En referencia a la ocupación (Gráfico 1), en Río Gallegos todos manifestaron realizar algún tipo de trabajo, a excepción de dos jubilados y uno que no trabaja. Entre quienes trabajan en administración pública ninguno tiene relación laboral directa con áreas relacionadas al patrimonio cultural. El alto porcentaje de empleados públicos se dividen en veintiuno en el ámbito provincial y tres en el municipal.

Respecto de la edad, la más joven tiene 21 años, por lo cual no hubieron encuestados debajo de ese rango dividiendose un $46 \%$ en mayores de 40 años de los cuales solamente tres tienen la misma edad que tiempo de residencia, mientras que aquellos incluídos en el rango etario de 21 a 40 años (27 encuestados), el 63\% de ellos tienen la misma edad que tiempo de residencia, con algunos pocos casos de no haber estado en la localidad por un tiempo.

En cuanto a la perspectiva de género no se comprobó que fuera relevante a la hora de definir el patrimonio cultural, si bien es marcada la relación laboral tanto entre quienes se desempeñan en la docencia o en la administración pública que es mayormente femenina.

\section{La noción de patrimonio cultural desde la perspectiva de los actores locales}

En Puerto Deseado, la definición que dieron los encuestados respecto a qué entendían por patrimonio cultural fue diversa dado que era una pregunta abierta (Gráfico 2). Los que 
estuvieron vinculados de alguna forma con el patrimonio cultural dieron una explicación más precisa acerca del mismo.

Un 43,5\% se acerca a algún componente de la definición legal cuando sostienen que "es un conjunto de elementos que representan a un lugar, un grupo o la cultura de los mismos", "el cuidado de lugares/edificios/monumentos característicos y representativos de un lugar", "edificio o manifestación cultural originaria del lugar, tradiciones y folclore. Somos un pueblo de inmigrantes con una variedad cultural", "elemento lugar o edificio que tenga un legado histórico cultural para una comunidad", "conjunto de bienes de valor histórico cultural y arquitectónico que conforman nuestra identidad y nos definen como sociedad", "todo aquello que tiene un valor histórico", "lugares, edificio, monumentos, relatos históricos que identifican un lugar", "aquello que perdura y se conserva en el tiempo material o no", "aquel elemento o lugar que es representativo y marcó la evolución social de una comunidad, aquello que completa identidad", "instituciones o lugares que a lo largo de la historia marca como referencia de un lugar", "se debe resguardar porque es lo más preciado que nos queda como memoria de época pasadas". Son bienes tangibles e intangibles con que las personas de una comunidad se sienten identificadas, "rico en arquitectura. Construcciones en chapa ostrilion o con bloques de roca trabajada por picapedreros".

\section{Gráfico 2: El Patrimonio cultural desde la perspectiva de los encuestados en Puerto Deseado y Río Gallegos}

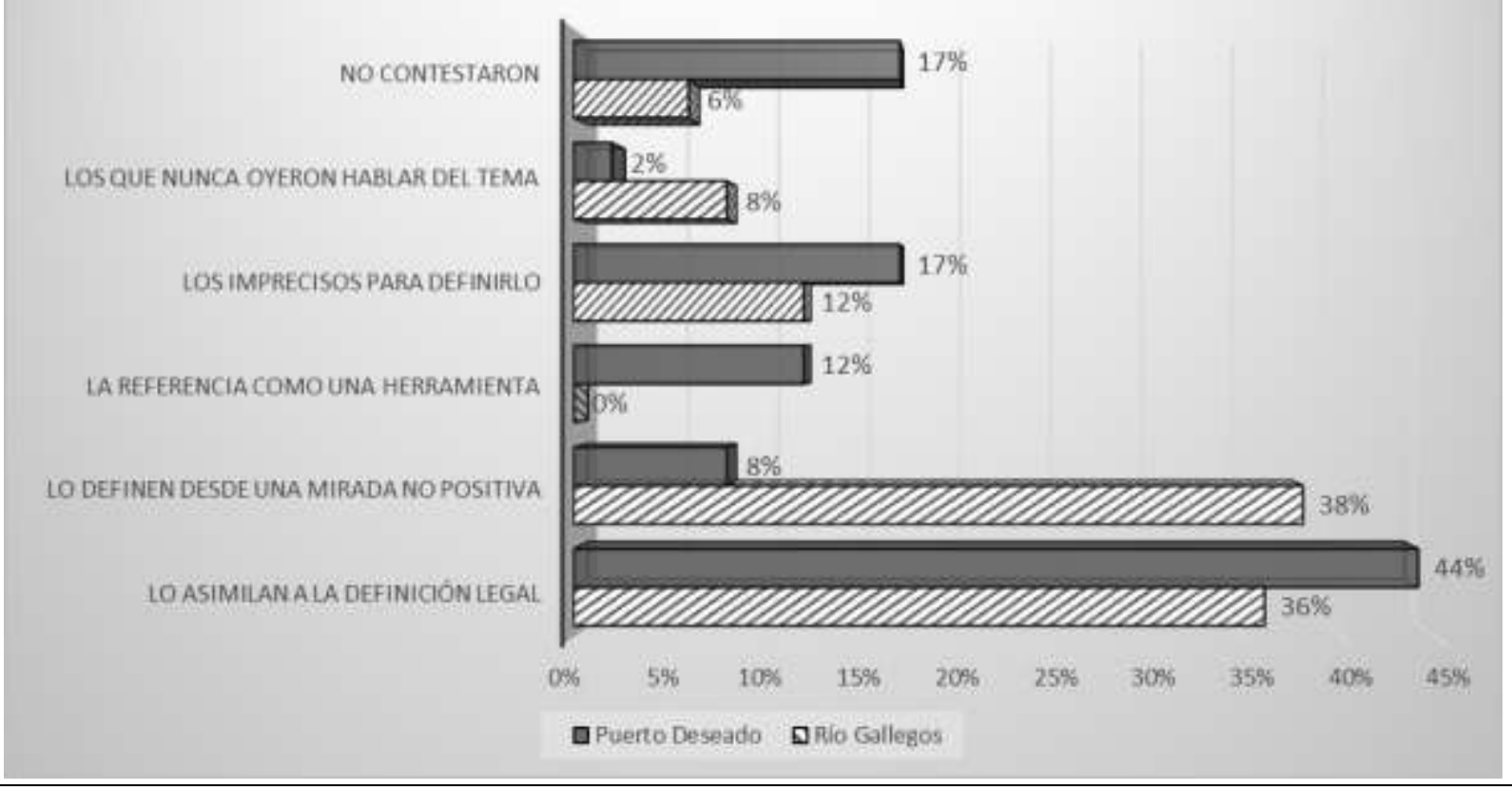

La definición que brinda la Ordenanza 8043 del patrimonio cultural en su artículo 3 es la siguiente: "está integrado por las obras del hombre, las obras conjuntas del hombre y la naturaleza y los recursos naturales que forman parte del ejido, los usos y costumbres, los paisajes culturales, las reservas naturales tangibles e intangibles y todos aquellos bienes que posean un carácter histórico, antropológico, etnográfico, arqueológico, artístico, arquitectónico urbano, científico e inmaterial incluido el patrimonio natural cultural viviente". En el siguiente párrafo del mismo artículo clasifica al patrimonio cultural en tangible e 
intangible. Han sido las convenciones internacionales las que permitieron la elaboración conceptual de la noción de patrimonio que se fue modificando a través del tiempo y, en todos los casos, supone una red compleja de relaciones con otros elementos. En la norma municipal la noción patrimonio cultural ha sido contemplada en sentido amplio cubriendo las distintas categorías en que éste puede subdividirse y si bien a primera vista es taxonómica deja abierta la posibilidad de seguir creando categorías a través de nuevas Ordenanzas.

Un 8,33 \% lo define desde una mirada no positiva como "abandonado, falta de mantenimiento", "deja mucho que desear. No tienen gente apta para cuidar nuestra cultura", "descuidado con falta de preocupación por desconocimiento y amor por nuestra historia y elementos que la representan", "nos falta bastante educación para cuidar y defender nuestro patrimonio, está bastante descuidado",

Un $12,50 \%$ lo referencia como "herramienta potencial histórica y turística", "herramienta para hacer crecer la ciudad y conocer su historia", "herramienta importante para la cultura" y con la posibilidad de "creación de áreas referentes al patrimonio", "determinante para todas las generaciones".

Entre los que son imprecisos o inespecíficos para definirlo "que se encuentra en buena conservación", "importante el patrimonio cultural sin explotar y sin cuidar", "es algo que día a día crece, se hace conocido y se valora mucho más"; los que no contestaron y los que manifiestan no haber oído nunca hablar del tema patrimonial suman un 35,42\%.

De este modo, puede inferirse que aproximadamente un 64,58 \% de la población posee alguna información o conocimiento sobre el tema que fue adquirido por estar en contacto con alguna institución relacionada a la educación o a los espacios culturales o turísticos de Puerto Deseado. El porcentaje restante es ambiguo o no sabe, existiendo una correlación entre la edad, el tiempo de residencia en la localidad y el trabajo que realiza.

En Río Gallegos (Gráfico 2) los encuestados se inclinan en definir al patrimonio cultural dentro de dos categorías de análisis muy diferentes entre sí, el 36\% lo definen con conceptos muy cercanos a la definición legal, donde la historia, costumbres, legado, herencia son términos utilizados por ellos. Definiciones tales como "El valor histórico, valor social, que da identidad al lugar que pertenece", "La historia de la ciudad", "Herencia de una sociedad, la cultura comprensible de costumbres, estructuras, puede ser material o inmaterial", como también otras que dijeron "Derechos de todos", "Es la esencia de un pueblo" y "La herencia que nos queda a las personas de lo construido o lo realizado porque también puede ser una idea, no algo tangible". En todas estas respuestas hay presencia de lo material, inmaterial, lo hereditario, el derecho, lo social.

En las definiciones no positivas (38\%) sobre cómo definen el patrimonio cultural, las respuestas hacen referencia sobre el estado de los elementos patrimoniales o el interés escaso que muestran "otros" sobre el mismo. "Escaso. No me parece que haya una búsqueda de las raíces, será porque hay mucha gente de paso y a que es un lugar nuevo", "Importante, mal conservado, mal cuidado"; "Con mucha falta de atención. No le dan importancia"; "Muy poco patrimonio cultural pero descuidado"; "Pobre, no ha mucho y cuando hay no hacen mucho para informar"; "Pobre, en vías de extinción".

En cuanto a los elementos mayormente seleccionados en Puerto Deseado (Gráfico 3) ellos forman parte de la arquitectura histórica de la localidad. La que se lleva el mayor reconocimiento es la estación ferroviaria, un extraordinario edificio construido con piedras de 
la zona en 1909-1910, labradas a mano, declarado Monumento Histórico Municipal en 1990 y de Interés Turístico por la Secretaría de Turismo de la Nación. Hoy, la estación no sólo es museo ferroviario creado por ex ferroviarios sino archivo histórico municipal y museo del pueblo, tema que se ampliará más adelante.

El segundo elemento seleccionado es el Cine teatro español, que data del año 1915, por años estuvo en manos de la municipalidad por medio de un comodato y en el último año se activó como espacio social y cultural a partir de la conformación de una asociación civil que pretende restaurarlo para realizar actividades sociales allí.

En el mismo rango han sido colocados el frigorífico CAP y la Gruta de Lourdes, el primero vinculado a la actividad ganadera predominante en la zona desde los inicios del poblamiento y el segundo por ser un lugar de peregrinaje importante no sólo para Puerto Deseado sino para las ciudades de la zona norte de Santa Cruz y sur de Chubut. Los cañadones circundantes y la ría Deseado conforman el paisaje natural por el que la ciudad ocupa un lugar en las ofertas turísticas santacruceñas. Vinculado a la historia de la ría se encuentran el muelle Ramón como primer embarcadero y el Museo Brozozki que guarda los restos de la Corbeta inglesa Swift hundida en las proximidades de la localidad y que forma parte del patrimonio arqueológico subacuático local con reconocimiento internacional.

\section{Gráfico 3: Selección de objetos, edificios y lugares en Puerto Deseado y Río Gallegos}

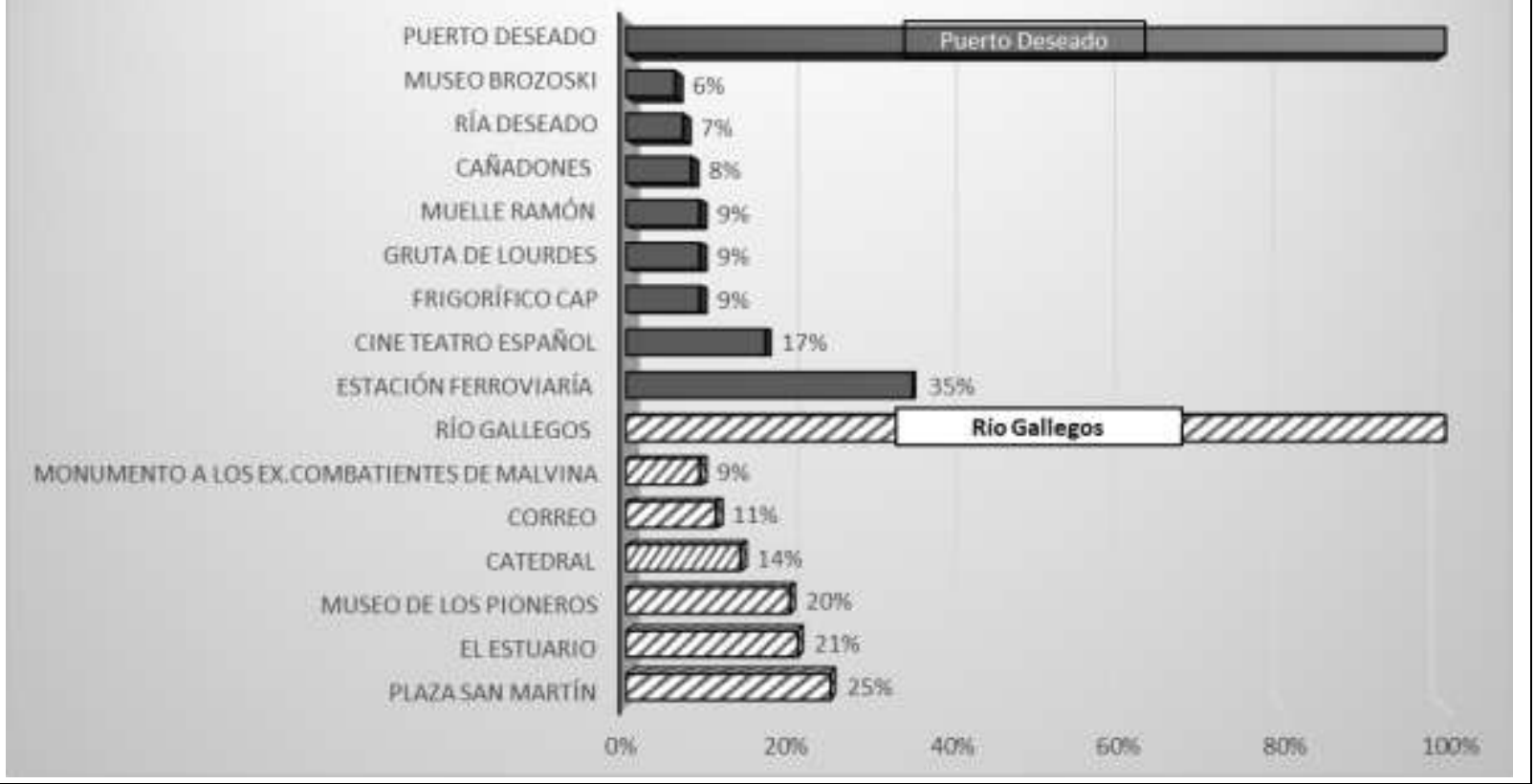

En Río Gallegos (Gráfico 6) uno de los elementos más seleccionados es el estuario reconocido como espacio natural, de recreación (en la actualidad) vinculado fuertemente a la historia productiva del lugar (ramal férrea y puerto de YCF y del frigorífico Swift). Otros mencionados son los edificios históricos (Municipalidad, Catedral, Correo y la Plaza Central) además del Monumento a los ex combatientes de Malvinas. Un pequeño porcentaje asigna valor representativo a las avenidas principales. Respecto de los dos los más seleccionados fueron la Plaza San Martín, y el Estuario/Ría, es decir vinculado a lo construido, tangible, con 
recuerdos, espacio de encuentro, parte de la historia de la ciudad. Y a lo natural, por su belleza, costanera, lugar para paseo, la vista. Pero también hubo un tercer lugar dentro de la elección que es el Museo de los Pioneros, lugar de gran historia, que es nombrada por los encuestadores también como Casa Parisi, fue declarada Patrimonio Histórico Cultural, por decreto en el mes de diciembre 2009.

En cuanto a los declarados, la mayoría no sabía exactamente cuáles eran, pero varios sospechaban de algunos edificios declarados. Aquí también se manifiesta el desconocimiento de las Ordenanzas, porque no conciben la existencia de zonas patrimoniales o áreas urbanas protegidas.

\section{Las Ordenanzas y los mecanismos de acceso a la información y a la participación}

En Puerto Deseado (Gráfico 4), un $63 \%$ de los encuestados reconoce no saber de la existencia de una Ordenanza. Del $37 \%$ que declaró conocerla, las opiniones que brindan no permiten establecer qué grado de conocimiento tienen dado que las respuestas son ambiguas y generales. Por ejemplo, responden: "debe difundirse a la sociedad", “es fundamental", "está incompleta", "es bueno siempre y cuando se cumpla, hay que integrar a diversos actores de la localidad", "faltaría actualizarla", "debería ser más respetada", "sé que existe y de la participación de gente de Puerto Deseado", "existe, pero no dan participación", "falta estudio sobre el tema".

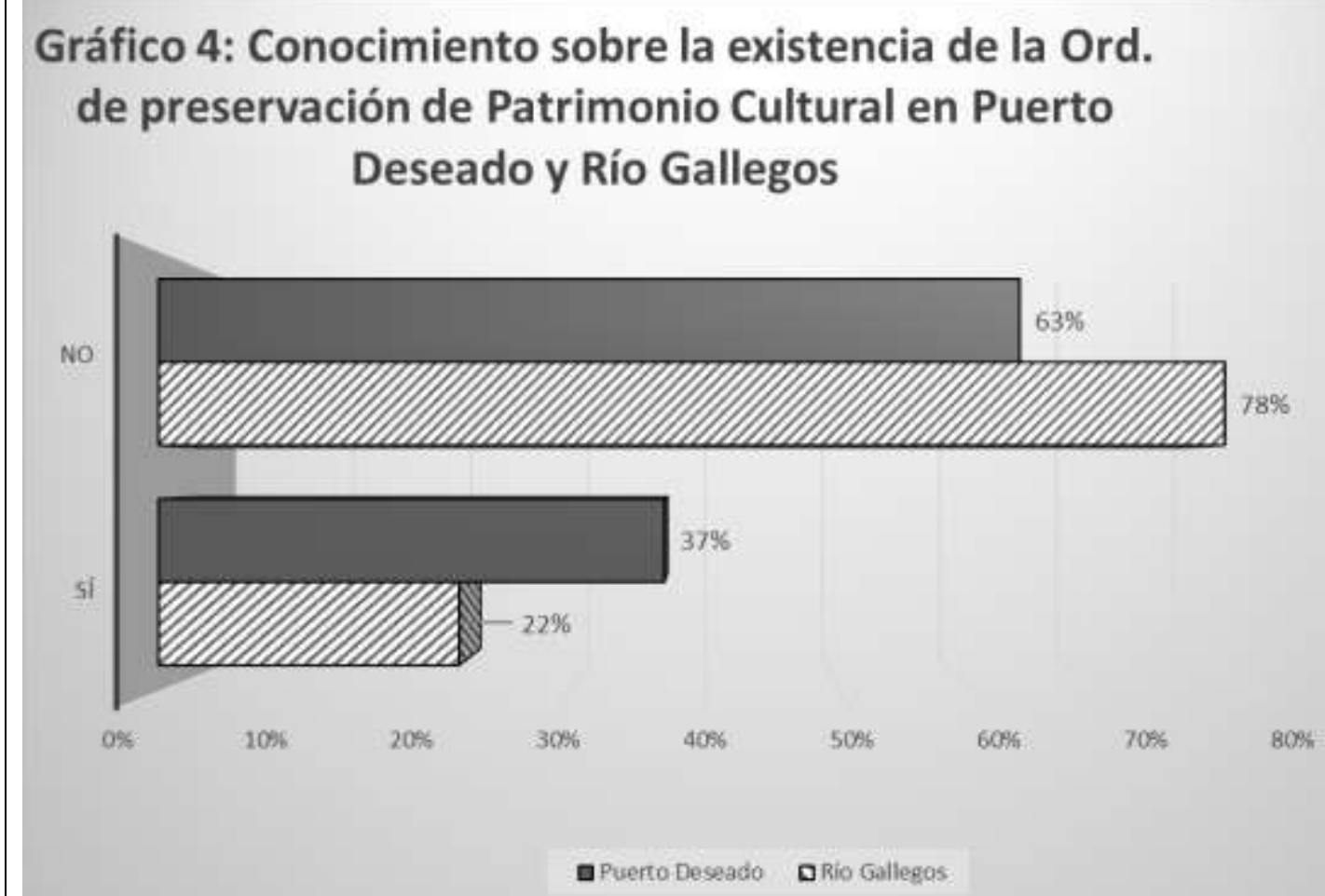

Dos respuestas, más allá de su ambigüedad, son relevantes: la primera "excelente trabajo elaborado por una especialista en patrimonio" y la segunda que menciona que "la Ordenanza tiene errores", sin especificar cuáles son. En el primer comentario se hace referencia a que la propuesta de esta Ordenanza la realizó la abogada especialista Ana María Bóscolo entre los años 2012 y 2014 quien al plantear el ámbito de vigencia de la futura norma y los principios 
generales para su interpretación en los artículos 1 y 2 propuso la aplicación subsidiaria, en caso de supuestos legislativos, de los artículos $16^{10}$ y 17 del viejo Código de Vélez Sársfield. El proyecto de Bóscolo se convirtió en Ordenanza 6716 del Honorable Concejo Deliberante durante el año 2017, ya con plena vigencia del nuevo Código Civil y Comercial (Ley 26.994/2015) que modificó sustancialmente al anterior.

El Código Civil y Comercial vigente inicia con un Título preliminar que aporta reglas acerca de cómo debe interpretarse. En su primer artículo, "Fuentes y aplicación ${ }^{11 "}$ queda claramente planteado que forma parte de un "sistema jurídico que debe respetar principios y derechos contenidos en instrumentos jurídicos de mayor jerarquía”. Por un lado, sienta las bases axiológicas del derecho privado y, por otro, sirve de guía para resolver cualquier caso mediante la aplicación de fuentes que deben respetar la Constitución Nacional y los Tratados de Derechos Humanos en los que el país sea parte (tanto aquellos enumerados en el artículo 75, inciso 22, o los ratificados por el Estado como, en un segundo nivel, los usos, prácticas y costumbres cuando las leyes o los interesados se refieren a ellos, en situaciones no regladas legalmente o siempre que no sean contrarios al derecho). Como puede apreciarse, el nuevo Código de derecho privado no es ajeno a la perspectiva de derechos humanos que ha impactado de manera directa en el mundo legal ${ }^{12}$ y en el desarrollo jurisprudencial y doctrinario que ha colocado a los derechos colectivos (ambientales, culturales) en un lugar de debate dentro de la sociedad. Al regular las pautas de interpretación en el artículo $2^{13}$, el Código vigente apela nuevamente a los tratados de derechos humanos y al permanente diálogo entre todo el sistema jurídico argentino.

Cuando el encuestado menciona que la Ordenanza "tiene errores" está en lo cierto, ya que, si bien los concejales dan cuenta de la vigencia del nuevo Código Civil y Comercial no han verificado la correlación entre los viejos y nuevos artículos. Cuando debieron haberse reemplazado los artículos 16 y 17 del Código de Vélez por los artículos 1 y 2 del nuevo $\mathrm{CCyC}$, se dejaron los viejos artículos que hacen referencia a otras cuestiones (bienes y cosas y derechos sobre el cuerpo humano). Este error debería subsanarse.

10 Art. 16 (del Código Civil de Vélez Sársfield): Si una cuestión civil no puede resolverse, ni por las palabras, ni por el espíritu de la ley, se atenderá a los principios de leyes análogas; y si aún la cuestión fuere dudosa, se resolverá por los principios generales del derecho, teniendo en consideración las circunstancias del caso.

Art. 17 (del CCVS). Los usos y costumbres no pueden crear derechos sino cuando las leyes se refieran a ellos o en situaciones no reguladas legalmente.

11 Art. $1^{\circ}$ (del nuevo Código Civil y Comercial). Fuentes y aplicación. Los casos que este Código rige deben ser resueltos según las leyes que resulten aplicables, conforme con la Constitución Nacional y los tratados de derechos humanos en los que la República sea parte. A tal efecto, se tendrá en cuenta la finalidad de la norma. Los usos, prácticas y costumbres son vinculantes cuando las leyes o los interesados se refieren a ellos o en situaciones no regladas legalmente, siempre que no sean contrarios a derecho

12 Para ampliar esta argumentación pueden leerse los Fundamentos del Anteproyecto del Código Civil y Comercial de la Nación.

13 Artículo $2^{\circ}$ del CCyC. Interpretación. La ley debe ser interpretada teniendo en cuenta sus palabras, sus finalidades, las leyes análogas, las disposiciones que surgen de los tratados sobre derechos humanos, los principios y los valores jurídicos, de modo coherente con todo el ordenamiento. 


\section{Gráfico 5: Mecanismos de participación para la identificación y selección de bienes culturales en Puerto Deseado y Río Gallegos}

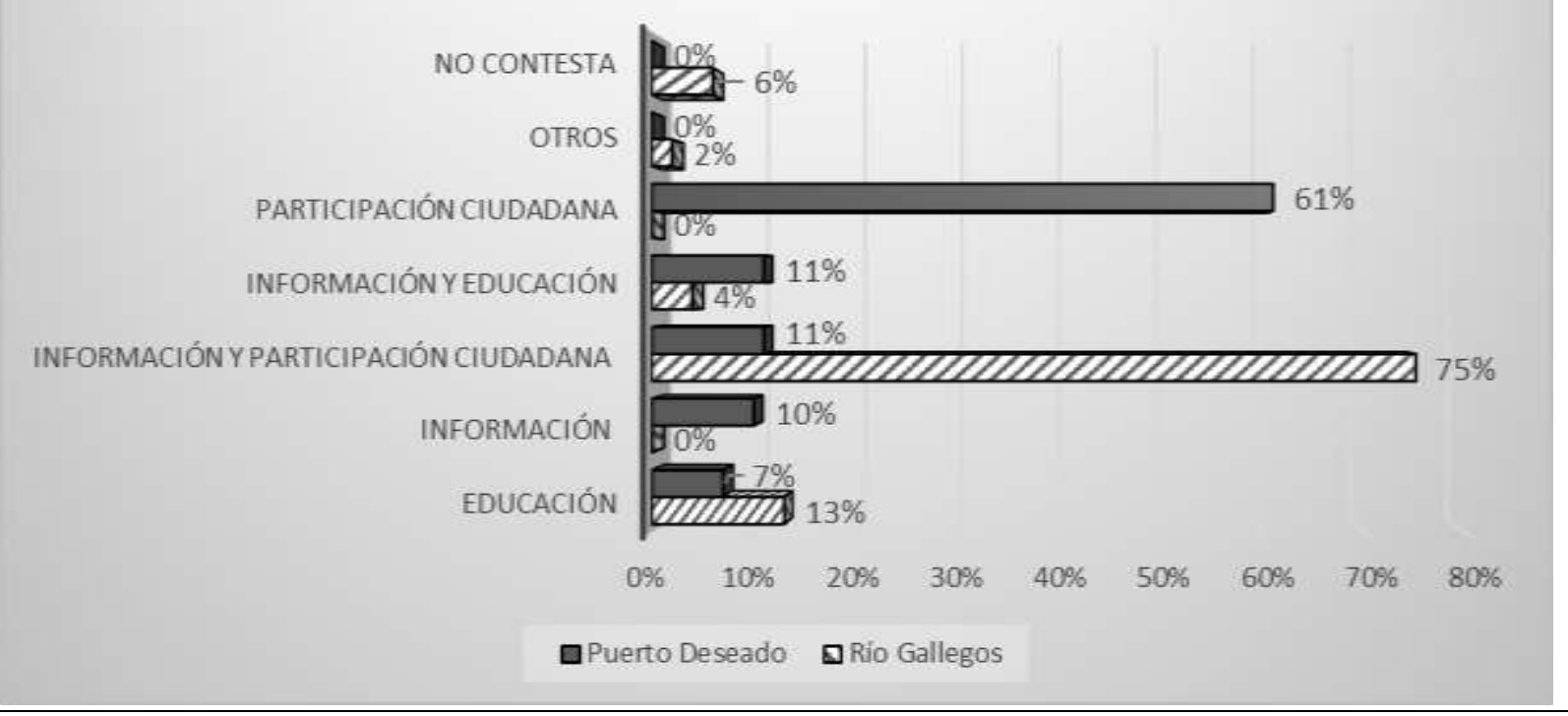

El gráfico 5 refleja las categorías que han permitido analizar los mecanismos que la comunidad considera en las cuestiones relativas a la identificación y selección de bienes culturales. En distintas ocasiones Katarina Tomasevski, Relatora especial de la ONU para el derecho a la educación, puso de relevancia el valor de ésta como "la puerta de entrada para todos los demás derechos humanos" y como "multiplicador que aumenta el disfrute de todos los derechos y libertades individuales cuando el derecho a la educación está efectivamente garantizado, y priva a las poblaciones del disfrute de muchos derechos y libertades cuando ese derecho se niega o viola" (2003). En el caso de los encuestados de Puerto Deseado un 7\% vincula la educación y la necesidad de generar conocimiento acerca de ese patrimonio con la posibilidad de actuar en torno a él. Un $11 \%$ vincula la educación formal e informal, a través de la realización de charlas temáticas, con la circulación de información. Se trata de pensar en la educación no solo desde un aspecto instructivo sino también en el poder transformador que tiene sobre las personas por cuanto permite el desarrollo de un pensamiento emancipador e interpretativo y para que no sea vulnerado es necesario que sea accesible para todos. La apropiación del patrimonio por parte de las personas, grupos o comunidades puede fortalecer las identidades sociales, la construcción del conocimiento histórico de la localidad y de la idea de sustentabilidad.

La producción y el acceso a la información aparece en el 32\% de los encuestados como un reclamo, vinculado a la difusión, por ejemplo, "con campañas publicitarias originales", "organizando charlas" en algunos casos combinado con otras dimensiones como la educativa pero también vinculado a la participación ciudadana. La información es un insumo que facilita la participación, el diseño de políticas públicas y la efectivización de derechos, tal como plantea x "luego de la concientización, a través de la consulta popular", "si hay ordenanza haciéndola cumplir y si no hubiera, creándola”. 
Puntualmente referido a la definición de los propios encuestados respecto a qué entienden por participación, algunas de las respuestas son las siguientes "acceder a las decisiones o sugerencias", "aportar a la protección del patrimonio cultural. Formar comisiones asesoras y movilizarse ante riesgos", "colaborar en el armado de proyectos y actividades para un determinado fin", "comprometerse a hacer cosas", "integración y compromiso", "intervención en una actividad o suceso determinado", "consulta popular", "la forma de actuar activa es a través del voto, la palabra o las acciones", "que se le permita al ciudadano aportar ideas e inquietudes", "ser activos en proponer ideas y realizar acciones", "ser parte de un proyecto o movimiento comunitario que busque una mejora para la comunidad", "que los ciudadanos podamos opinar sobre algunas decisiones a tomar", "tomar parte de la decisión con conocimiento de las causas y efectos de la decisión".

En referencia a qué mecanismos deberían implementarse para la selección de bienes culturales patrimonializables con miras de ser declarados, un $61 \%$ propuso acciones diversas que van desde las "audiencias públicas", "encuestas", "encuestas y votación”, ·a través de la formación de una asociación civil especializada", elevando "notas al Honorable Concejo Deliberante y a la Comisión de Patrimonio", "poniendo objetos a disposición", "armando una comisión donde se decida democráticamente y se seleccione", "cuidando los edificios que no sean dañados".

En Río Gallegos (Gráfico 10) más allá que el alto porcentaje (75\%) de los encuestados manifestó tener conocimiento de la Ordenanza por las respuestas que dieron posteriormente pareció ser más una presunción. En general apareció como subyacente la idea de que es el Estado el que debe promover la participación. Las respuestas sobre la opinión que le merecía las ordenanzas no son de posible análisis dado que son muy generales y sin definición puntual sobre la misma.

En relación de los mecanismos de participación en la Categoría Participación Ciudadana, las respuestas apuntan mayormente a la Votación, Juntas Vecinales y a las Encuestas, pero a su vez acompañada con una acción concreta, como charlas previas, utilización de redes sociales. Algunas de las respuestas fueron las siguientes: "Consulta popular, recibir propuestas de los vecinos, público en general por medios actuales o presentación personal y esto evaluado por el Concejo Deliberante"; "Encuestas barriales, cada barrio debe tener algo que lo distingue y debe ser reconocido"; "Encuestas, participación en lugares educativos". A su vez se fueron ampliando las respuestas siempre con mucha fuerza en la participación: "Difusión por los medios y participación de la gente en el sentido del patrimonio, su conservación" o "Foros de intercambio de ideas. Hay que generar y estimular participación de entidades colectivas que ya tienen iniciativa al respecto (escuelas de danzas, Clubes". Solo una persona (bastante joven) recordó que en su infancia se había movilizado un sector de la sociedad contra el cierre del cine Carrera, y que había firmado una petición. Posiblemente este comentario se relaciona con la implementación de la Ordenanza 7505 de 2011, que creó la Comisión de Protección, Promoción y elección de los Cafés, Bares, Billares y Confiterías Notables de la Ciudad de Rio Gallegos con el propósito de realizar la elaboración y actualización de un catálogo de difusión en los centros de actividades turísticas denominado Café notables. Si bien no ha aparecido en las encuestas, en su Informe Final, Bóscolo manifiesta que existen Organizaciones no gubernamentales involucradas con el patrimonio cultural como la Asociación de Arquitectos de la Provincia de Santa Cruz y el Consejo Profesional de la Provincia de Santa Cruz. 
Otro de los indicadores de progreso son los de proceso que buscan medir la magnitud de esfuerzos del Estado para implementar los derechos. El grado de avance de los derechos culturales permite pensar en prácticas ciudadanas posibles vinculadas tanto a la patrimonialización como a la generación de espacios propicios para la participación en la vida cultural que también pueden vincularse al patrimonio cultural. No se ha podido observar la existencia de campañas o programas que promocionen el derecho al patrimonio cultural.

\section{CONCLUSIONES}

El Estado argentino ha ratificado instrumentos internacionales que orientan las políticas públicas patrimoniales y dispone de diversas medidas para implementar los derechos culturales comprometidos tanto a nivel de existencia de un aparato institucional como legal en los diferentes niveles de gobierno. Es el encargado de la creación de organismos vinculados al desarrollo de los diversos aspectos de la cultura, de la sensibilización y aumento de capacidades de participación de individuos, grupos y comunidades y de la producción y distribución de la información acerca de los avances en los derechos culturales. Es decir, cuenta con la recepción de derechos y la capacidad estatal para efectivizarlos.

Sin embargo, los esfuerzos del Estado Nacional desde su consagración constitucional como derecho en 1994 y los avances a nivel provincial y municipal en la primera década del siglo XX parecen encontrarse limitados cuando se trata de implementar estrategias, programas o políticas destinadas al logro de las metas. Esa deficiencia en las acciones públicas, que afectan el grado de efectividad de los derechos culturales, se comprueban a partir de los indicadores de resultado y del insuficiente presupuesto destinado al desarrollo de programas de patrimonio cultural o al apoyo de asociaciones para la gestión del mismo.

La producción de información por parte del Estado que afecta la difusión y el acceso a la misma es también parte del problema, que se relaciona con otro que es la falta de reglamentación de las normas ya que a pesar de que existen leyes que contemplan los mecanismos de participación, en la práctica no logran efectivizarse.

Como señal de progreso cualitativa aparece el interés de la gestión municipal (Puerto Deseado) de generarlos y el activismo de asociaciones civiles en el uso social de los bienes culturales. Cada año cobran mayor presencia los grupos y las asociaciones no gubernamentales que defienden bienes que consideran representativos.

Las tensiones que se generan están ligadas al acceso a la información. Por parte de algunos actores de la sociedad civil existe cierto temor, infundado erróneamente, a que la patrimonialización "museifique" los bienes obstaculizando su refuncionalización o la restauración si se trata de un edificio, o que la declaratoria signifique restricciones de dominio para los propietarios.

La educación patrimonial aparece entonces como una herramienta clave no solo de la participación sino de la información. La generación de mecanismos que faciliten la participación amplia en programas referidos a distintos tipos de actividades culturales (como la identificación y selección de bienes patrimonializables), coloca al Estado como principal responsable del cumplimiento y protección de los derechos culturales a partir de la generación de políticas públicas que permitan la gestión de la cultura y aseguren la participación comunitaria cuando se trata del derecho al patrimonio cultural. 
La situación parece ser más clara en el caso del patrimonio cultural inmaterial donde el marco normativo internacional otorga el rol protagonista a las comunidades dado que la relación entre el PCI y las comunidades es vinculante. Tanto en el instrumento internacional ratificado como en sus Directrices que constituyen el soft law existen directivas de cómo debe ser la dinámica de la participación vinculada a la realización de fichas de relevamiento e inventarios, planes de salvaguardia y al rol de los sujetos. Los registros deben contemplar el contexto, el ámbito social y cultural de la comunidad; si bien la descripción del objeto patrimonial es importante no hay que desatender el proceso de patrimonialización y el rol de los sujetos intervinientes; incorporar a expertos en trabajo de campo como pueden ser los antropólogos como mediadores/traductores y facilitadores de la participación comunitaria con el fin de activar patrimonios comunitarios.

Son las propias comunidades las protagonistas y quienes deben ser consultadas y consentir si desean revelar información sobre su patrimonio a otros públicos mediante estas acciones y planes, son ellas las que deben proponer qué bienes deben patrimonializarse para ser preservados para las generaciones futuras.

Así como se plantean algunas certezas, del análisis de la normativa provincial y municipal y del Informe de 2012, que podría actuar como guía interpretativa de la ley provincial, quedan preguntas sin responder. La primera se relaciona con el significado de "activa participación ciudadana" que no se encuentra explicitado. Si bien la noción de participación podría interpretarse a partir de los lineamientos que dieron base a las ordenanzas municipales, parece serlo desde un concepto de participación restringido, limitado a las organizaciones no gubernamentales o asociaciones civiles cuyo objeto sea la protección del patrimonio cultural. Tampoco se ha podido determinar a qué se refiere con "personalidad acreditada" si en realidad es una forma de escritura heredada de normas anteriores o si en realidad se trata de una mirada restrictiva de quienes pueden participar.

De la normativa de Puerto Deseado y Río Gallegos se desprende que los funcionarios, referentes de las asociaciones, grupos culturales involucrados en el tema y ONGs pueden hacerlo. Pero ¿pueden participar el particular, el vecino y en qué situaciones? ¿pueden los docentes investigadores de las universidades formar parte de las Comisiones de Patrimonio? ¿cuándo y cómo serían convocados? Además de la Reglamentación de la norma municipal debería incluirse la noción de participación en la vida cultural prevista en la Observación 21 del Comité DESC. Vinculado a esta categoría se plantearon Indicadores de procesos y de resultados que hasta el momento no han podido determinarse. ¿Acaso quedan excluidos los individuos y los grupos y se estaría interpretando un modo de participación en la vida cultural (en este caso identificación y selección de bienes culturales) diferente al planteado por la Observación $\mathrm{N}^{\mathrm{o}} 15$ ?

Más allá de estas apreciaciones conceptuales es evidente que ha habido un avance cualitativo en la activación del patrimonio en ambas ciudades. En Puerto Deseado se han generado tanto desde el propio Estado municipal como desde la comunidad espacios culturales y uno de los ejemplos más claros es la creación del Museo ferroviario y recientemente el Museo del Pueblo. Respecto de la existencia de la normativa y de las posibilidades que se abren para quienes deseen hacerlo, la evidencia empírica da cuenta de la necesidad de una mayor información de lo que se está realizando o de lo que se puede realizar para evitar que quede 
concentrada en pocas personas o grupos la toma de algunas decisiones vinculadas al patrimonio de la localidad.

Indudablemente se trata de una construcción de derechos que es dinámica y que requiere de la apropiación de los actores estatales y no estatales de la idea que la preservación del patrimonio cultural no se trata solo de un derecho sino también de un deber vinculado a la herencia cultural de cada pueblo y a la calidad de vida de los habitantes del planeta.

\section{BIBLIOGRAFÍA}

ABRAMOVICH, V. (2007) "Los estándares interamericanos de derechos humanos como marco para la formulación y el control de políticas sociales", en ABRAMOVICH, V; BOVINO, A Y COURTIS, C (comps) La aplicación de los Tratados sobre Derechos Humanos en el ámbito local, La experiencia de una década. CELS/ Del Puerto, Buenos Aires. https://doi.org/10.5354/0718-2279.2006.13370

ABRAMOVICH, V. Y PAUTASSI, L. (2009) "El enfoque de derechos y la institucionalidad de las políticas sociales”. En ABRAMOVICH, V. Y PAUTASSI, L (comp.) La revisión judicial de las políticas sociales. Estudio de casos. Buenos Aires. Editores del Puerto. https://doi.org/10.18356/a48f3cca-es

AGUDO TORRICO, Juan (2003). "Patrimonio y derechos colectivos" en Serie Cuadernos Técnicos. Antropología y Patrimonio: investigación, documentación e intervención, Sevilla, IAPH.

ALVIRA MARTIN, F. (2004). "La encuesta: una perspectiva general metodológica", Cuadernos Metodológicos No 35, Madrid: Centro de Investigaciones Sociológicas.

BADENES, D. (2005). “Actores sociales y apropiación del patrimonio en una escala local. La Universidad platense en la pugna por una memoria de lo urbano", en La dimensión social del patrimonio, Buenos Aires, CICOP. https://doi.org/10.25145/j.pasos.2017.15.060

BANUS, L., ADLER, F. y otros (2013). "Breve reflexión en torno al nuevo Protocolo Facultativo al Pacto de Derechos Sociales, Económicos y Culturales" en Infojus. Sistema Argentino de Información Jurídica. https://doi.org/10.18356/a7e0b310-es

CISELLI, G (2001) "Los usos del pasado. Memoria, historia y esfera de lo público en los ferrocarriles del norte de Santa Cruz" Revista de Antropología Experimental (RAE), $\mathrm{N}^{\mathrm{o}}$ 1, Universidad de Jaén, España. https://doi.org/10.17561/rae.v19.02

CISELLI, G. (2014) El patrimonio cultural: debates actuales y múltiples miradas. Comodoro Rivadavia bajo el prisma patrimonialista. Comodoro Rivadavia. Ed. Vela al Viento. https://doi.org/10.4067/s0719-56052019000100153

CISELLI, G (2018) "El acceso a la participación como mecanismo de preservación del patrimonio cultural ante los gobiernos locales" en Revista Textos y Contextos desde el $\begin{array}{llllll}\text { Sur } & N^{\circ} & 6 . & \text { UNPSJB. } & \text { Pp. } & \text { 133-152. }\end{array}$ http://www.revistas.unp.edu.ar/index.php/textosycontextos/article/view/72 
CISELLI, G; DUPLATT, A. Y HERNÁNDEZ, M. (2019) “La normativa municipal aplicable al patrimonio industrial. Desafíos a las comunidades", En CISELLI, G. y HERNÁNDEZ, M. (2019). General Mosconi, un lugar con identidad petrolera. Tomo 3, Colección Historia y Patrimonio Patagónico. Ed. Biblioteca Popular Astra. https://doi.org/10.4067/s0719-56052018000100085

CISELLI, G.; HERNÁNDEZ, M. Y DUPLATT ANTONELLA. (2018). "El patrimonio cultural en la normativa municipal de Comodoro Rivadavia, Argentina (1985-2016)" en Revista Sophia Austral N² 21. Primer semestre. 2018- pp. 85-104. Universidad de Magallanes, Chile. https://doi.org/10.4067/s0719-56052018000100085

CISELLI, G. y HERNÁNDEZ, M. (2017) Astra. Memoria petrolera y paisaje industrial, Tomo 1, Colección Historia y Patrimonio Patagónico. Ed. Biblioteca Popular Astra.

CISELLI, G. y HERNÁNDEZ, M. (2015). "El derecho constitucional al patrimonio cultural. La movilización ciudadana como recurso frente al Estado Municipal” en CISELLI, G. y HERNÁNDEZ, M. (comps). El patrimonio industrial petrolero como expresión de las huellas del trabajador en el territorio. El caso de Y.P.F. en Comodoro Rivadavia y su impronta cultural. Buenos Aires. Ed. Dunken. https://doi.org/10.25145/j.pasos.2016.14.063

CISELLI, G. y LEVRAND, N. (2018) "Producir conocimientos sobre el Derecho Humano a los patrimonios culturales: cuestiones disciplinares y participación ciudadana en dos proyectos de Santa Cruz y Entre Ríos", ponencia presentada en $1^{\circ}$ Encuentro Nacional "Derechos Humanos y Educación Superior". Paraná.

COMISIÓN INTERAMERICANA DE DERECHOS HUMANOS (CIDH) (2008). Lineamientos para la elaboración de indicadores de progreso en materia de derechos económicos, sociales y culturales. Washington. https://doi.org/10.35537/10915/71690

COMITÉ DE DERECHOS ECONÓMICOS, SOCIALES Y CULTURALES, Observación general $\mathrm{N}^{\mathrm{o}}$ 21, Derecho de toda persona a participar en la vida cultural, E/C.12/GC/21/Rev. 1, 17 mayo de 2010. https://doi.org/10.5354/0718$\underline{2279.2006 .13379}$

CONSEJO ECONOMICO SOCIAL (2016). Informe del Grupo Interinstitucional y de Expertos sobre los Indicadores de los Objetivos de Desarrollo Sostenible. https://doi.org/10.18356/fdc72e34-es

COURTIS, C. (2010) "Apuntes sobre la elaboración y utilización de indicadores en materia de derechos económicos, sociales y culturales" en ARCIDIACONO, P.; ESPEJO YAKSIC, N.; RODRÍGUEZ GARAVITO, C. Derechos sociales, justicia política y economía en América Latina, Colombia, Siglo de Hombre Editores. https://doi.org/10.35537/10915/71690

DUPLATT, A. (2017) "Las políticas patrimoniales: del municipio al barrio”. En CISELLI, G. y HERNÁNDEZ, M. Astra. Memoria petrolera y paisaje industrial. Comodoro Rivadavia: Ed. Biblioteca Popular Astra. 
GRUPO DE TRABAJO PROTOCOLO DE SAN SALVADOR (2015) Indicadores de progreso para medición de derechos contemplados en el Protocolo de San Salvador. GT para el análisis de los Informes nacionales del Protocolo de San Salvador. Organización de Estados Americanos (OEA), Washington D.C. https://doi.org/10.5354/0719-3769.1987.15770

HARVEY, E. (2008) "Derecho a participar en la vida cultural (artículo 15 (1) (a) del Pacto). Instrumentos normativos internacionales y políticas culturales nacionales". Documento presentado ante el Comité de Derechos Económicos Sociales y Culturales. Ginebra. Naciones Unidas. https://doi.org/10.5354/0718-2279.2005.13352

LACARRIEU, M. (2018) "Patrimonio Cultural Inmaterial y Participación Comunitaria", Módulo del Curso de Posgrado en Gestión y Salvaguardia del PCI, Facultad de Ciencias Económicas, Universidad Nacional de Córdoba, Argentina. https://doi.org/10.19137/perspectivas-2019-v9n2a07

LORENZETTI, R. (1996): “Responsabilidad colectiva, grupos y bienes colectivos", en La Ley, Buenos Aires.

LORENZETTI, R. (2009) Teoría del Derecho ambiental, Buenos Aires, La Ley.

LOZA SERRA, M. R. (2015) "Límites a los derechos: el ejercicio abusivo de los derechos desde la perspectiva del ambiente como derecho de incidencia colectiva" en DEVIA, L. Avances del Nuevo código Civil y Comercial de la Nación en los aspectos ambientales, Buenos Aires, Ed. Albremática. https://doi.org/10.4067/s0718$\underline{68512016000200013}$

ORLANDO, L. A (2017) Las ONGs en el nuevo Código Civil y Comercial de la Nación en Argentina, en Microjuris.com. Disp. en https://aldiaargentina.microjuris.com/2017/02/17/las-ong-en-el-nuevo-codigo-civil-y$\begin{array}{llll}\text { comercial-de-la-nacion/ } & \text { (consulta } & 28 & \text { junio }\end{array}$ https://doi.org/10.14409/ne.v0i10.6239

PAUTASSI, L. (2010). Indicadores en materia de derechos económicos, sociales y culturales. Más allá de la medición. En ABRAMOVICH, V y PAUTASSI, L Medición de Derechos en las Políticas Sociales. Editores del Puerto. https://doi.org/10.35537/10915/71690

PAUTASSI, L. (2018). "El acceso a la justicia en Salud. Un análisis desde los mecanismos de monitoreo del Sistema Interamericano". Versión del artículo publicado en inglés en Health and Human Rights Journal. Harvard University Press. https://doi.org/10.1590/s1851-82652008000300002

PÉREZ ORTEGA, G.; ARANGO SERNA, M. y SEPULVEDA ATEHORTUA, L. (2011) "Las organizaciones no gubernamentales -ONG-: hacia la construcción de su significado" En Ensayos de economía No.38 Disp. En http://www.bdigital.unal.edu.co/29490/1/27942-98991-1-PB.pdf (consulta 1 de abril de 2019).

PINZÓN CAMARGO, M. A. (2005) "El papel de las ONG y sus alcances en la responsabilidad social empresarial" En Revista Ópera, vol. 5, N ${ }^{\mathrm{a}}$ 5, pp. 75-96 Universidad Externado de Colombia Bogotá.

PRATS, L. (2004). Antropología y patrimonio. Barcelona, Ariel. 
ROITTER, M. M. y Gonzalez Bombal, I. (Comps.) (2000) Estudios sobre el Sector Sin Fines de Lucro en Argentina. Centro de Estudios de Estado y Sociedad.

TOMASEVSKI, K. (2003). Contenido y vigencia del derecho a la educación. San José, C. R. Instituto Interamericano de Derechos Humanos. $26 \mathrm{p}$.

TORRES-MELO, J. Y SANTANDER, J. (2013). Introducción a las Políticas Públicas: Conceptos y herramientas desde la relación entre Estado y ciudadanía. Instituto de Estudios del Ministerio Público. Bogotá, D. C., Colombia. 